\title{
Morphological and molecular characterization of three new Parastenocarididae (Copepoda: Harpacticoida) from caves in Southern Italy
}

\author{
Maria Cristina BRUNO ${ }^{1, *}$, Vezio COTTARELLI ${ }^{2}$, Federico MARRONE $^{3}$, \\ Rosario GRASSO ${ }^{4}$, Erika STEFANI ${ }^{5}$, Luca VECCHIONI ${ }^{6} \&$ Maria Teresa SPENA ${ }^{7}$ \\ ${ }^{1,5}$ Research and Innovation Centre, Fondazione Edmund Mach, Via E. Mach 1, \\ 38010 San Michele all'Adige (TN), Italy. \\ ${ }^{2}$ Department for Innovation in Biological, Agro-food and Forest Systems, \\ Tuscia University, Largo dell'Università snc, 01100 Viterbo, Italy. \\ ${ }^{3,6}$ Department of Biological, Chemical and Pharmaceutical Sciences and Technologies, \\ University of Palermo, Via Archirafi 18, 90123, Palermo, Italy. \\ ${ }^{4,7}$ Department of Biological, Geological and Environmental Sciences, Catania University, \\ Via Androne 81, 95124 Catania, Italy. \\ *Corresponding author: cristina.bruno@fmach.it \\ 2Email: cottarel@unitus.it \\ ${ }^{3}$ Email: federico.marrone@unipa.it \\ 르ail: rosagra@unict.it \\ ${ }^{5}$ Email: erika.stefani@fmach.it \\ ${ }^{6}$ Email: luca.vecchioni@unipa.it \\ ${ }^{7}$ Email: marisaspena@hotmail.com

\footnotetext{
${ }^{1}$ urn:lsid:zoobank.org:author:EDA0F9BE-951D-4836-AFC7-B5D121A25476

${ }^{2}$ urn:1sid:zoobank.org:author:C6C2CE60-7F5D-4E61-9936-7B8702FB6739

${ }^{3}$ urn:1sid:zoobank.org:author:1F8EA78D-8B34-400F-A3DE-1F62F2B64593

${ }^{4}$ urn:1sid:zoobank.org:author:BEE38821-79B3-4981-962F-2E9E031FDDAB

${ }^{5}$ urn:lsid:zoobank.org:author:5333B94E-E03F-4D0A-9811-4591D8DBF09F

${ }^{6}$ urn:1sid:zoobank.org:author:6CA29348-C6DC-4BC2-871D-884E78443932

${ }^{7}$ urn:lsid:zoobank.org:author:1312A860-882A-4094-8FC6-58E2306194F4
}

\begin{abstract}
We describe three new parastenocaridid: Cottarellicaris sanctiangeli Bruno \& Cottarelli sp. nov., Stammericaris vincentimariae Bruno \& Cottarelli sp. nov. and Proserpinicars specincola Bruno \& Cottarelli sp. nov., collected in the pools of five different caves located in Calabria (Southern Italy). We conducted a phylogenetic analysis based on the mitochondrial COI and ribosomal $18 \mathrm{~S}$ sequences of $C$. sanctiangeli sp. nov. and $S$. vincentimariae sp. nov., and of four more species of Stammericaris and one Proserpinicaris available from literature. Based on the molecular study, the specimens of $C$. sanctiangeli $\mathrm{sp}$. nov. are clearly separated from the species belonging to the closelyrelated genus Stammericaris. The morphological and molecular data indicate that the genera belonging to the two subfamilies Parastenocaridinae and Fontinalicaridinae form two monophyletic and distinct clades, thus supporting their status. We also provide insights on the genus Proserpinicaris based on
\end{abstract}


morphological data only; in particular, the most important synapomorphic character of the genus, i.e., the taxonomic value of the hyaline structure inserted on the anterior surface of the male leg 4 basis, is discussed based on the development of the P4 endopod, as observed in the last copepodid stage of some species of this genus. Finally, we widen the biogeographic and ecological knowledge of the three genera.

Keywords. Crustacean, COI gene, 18S rDNA gene, karstic cave, evaporitic cave, stygofauna.

Bruno M.C., Cottarelli V., Marrone F., Grasso R., Stefani E., Vecchioni L. \& Spena M.T. 2020. Morphological and molecular characterization of three new Parastenocarididae (Copepoda: Harpacticoida) from caves in Southern Italy. European Journal of Taxonomy 689: 1-46. https://doi.org/10.5852/ejt.2020.689

\section{Introduction}

The taxonomy of the species-rich family Parastenocarididae Chappuis, 1940 has been widely studied and modified in the last few years. Firstly, new genera were erected based on new material (e.g., Cottarelli et al. 2010; Karanovic \& Cooper 2011a; Ranga Reddy et al. 2014). Secondly, the large genus Parastenocaris Kessler, 1913 was split with some of its species attributed to new genera or genera resurrected from those described by Jakobi (1972). Cottarellicaris (subfamily Parastenocaridinae Chappuis, 1940) was proposed by Schminke (2013), who raised the Parastenocaris hera species group (Berera \& Cottarelli 2003) to the genus level, adding two more species to it. The genus Cottarellicaris includes the following eleven species: C. gallicus (Chappuis \& Rouch, 1959), C. andalusica (Enckell, 1965), C. hera (Cottarelli, 1969), C. stellae (Cottarelli, Saporito \& Puccetti, 1981), C. numidiensis (Rouch, 1987), C. rivi (Cottarelli \& Bruno, 1994), C. etrusca (Cottarelli, Bruno \& Venanzetti, 1995), C. oligoalina (Cottarelli, Bruno \& Venanzetti, 1995), C. aphroditis (Cottarelli \& Bruno, 1997), C. sibaritica (Berera \& Cottarelli, 2003) and C. luciae (Cottarelli, Bruno \& Berera, 2008).

The genus Stammericaris (subfamily Parastenocaridinae) was redefined by Schminke (2013) who combined it with Phreaticaris Jakobi, 1972. The genus currently includes the following ten species: S. phreatica (Chappuis, 1936), S. stammeri (Chappuis, 1937), S. orcina (Chappuis, 1938), S. acherusia (Noodt, 1955), S. amyclaea (Cottarelli, 1969), S. pasquinii (Cottarelli, 1972), S. trinacriae (Pesce, Galassi \& Cottarelli, 1988), S. lorenzae (Pesce, Galassi \& Cottarelli, 1995), S. diversitatis (Cottarelli \& Bruno, 2012), S. destillans Bruno \& Cottarelli, 2017, plus one further species from Northern Italy presently being studied. As already discussed by Schminke (2013), some of the diagnostic characters of the genera Cottarellicaris and Stammericaris are similar, and these two genera can be considered sister taxa. In fact, they share a synapomorphic morphology in the endopod P4 of the male (a complex two-branched hyaline structure) with the distal outgrowth transformed differently and represent an autapomorphy for Cottarellicaris (an elongate lamella) as well as a plesiomorphy for Stammericaris (a seta).

The genus Proserpinicaris Jakobi, 1972 (subfamily Fontinalicaridinae Schminke, 2010), was redefined by Karanovic et al. (2012) who attributed 20 species to this genus; two species were later added by Totakura et al. (2014). The species currently attributed to the genus are the following: Proserpinicaris admete (Cottarelli, Fasano, Mura \& Saporito, 1980), P. amalasuntae (Bruno \& Cottarelli, 1998), P. cantabrica (Chappuis, 1937), P. corgosinhoi Totakura, Reddy \& Shaik, 2014, P. cruzi (Noodt \& Galhano, 1969), P. dubia (Kiefer, 1932), P. gorganensis (Kovalchuk \& Kovalchuk, 1990), P. hispanica (Martinez Arbizu, 1997), P. ima (Cottarelli, 1989), P. imjin Karanovic, Cho \& Lee, 2012, P. kalypso (Pesce, Galassi \& Cottarelli, 1988), P. karanovici Totakura, Reddy \& Shaik, 2014, P. mangini (Rouch, 1992), P. meridionalis (Rouch, 1990), P. moravica (Sterba, 1965), P. nicolasi (Rouch, 1996), P. nipponensis (Chappuis, 1955), P. ondali (Lee \& Chang, 2009), P. phyllura (Kiefer, 1938), P. proserpina (Chappuis, 1938), P. wangpi Karanovic, Cho \& Lee, 2012 and P. young Karanovic, Cho \& Lee, 2012. The controversial nature of the 
BRUNO M.C. et al., New Parastenocarididae (Copepoda, Harpacticoida) from Southern Italy

key synapomorphy of the genus Proserpinicaris, i.e., the presence of a hyaline process on the anterior surface of basis, between the exopod and endopod, was discussed by Corgosinho et al. (2012), but the genus definition of Karanovic et al. (2012) was accepted by other authors while describing new species of Proserpinicaris (Totakura et al. 2014; but see Walter \& Boxshall 2019). We will follow Karanovic et al. (2012) only in part, as we will discuss in detail.

The first molecular approaches to the definition of species boundaries and the study of phylogenetic relationships were conducted for lineages of Australian Parastenocarididae (Karanovic \& Cooper 2011a, 2011b). For Palaearctic Parastenocarididae, this approach has been applied only recently, because some diagnostic morphological characters of certain taxa are equivocal (Bruno et al. 2017), and the coupled molecular and phylogenetic approach is a useful tool to complement traditional, morphology-based taxonomic classification, and to understand species delimitations and evolutionary relationships. Bruno et al. (2017) investigated the validity and affinities of the genus Stammericaris and showed how this genus is well-separated from the genus Proserpinicaris, supporting the attribution of the two genera to the two different subfamilies of Schminke (2010). However, the same authors advocated the need of adding additional parastenocaridid species to the analysis, in order to improve the understanding of the family. In the context of our ongoing research on the microcrustacean fauna of caves in Southern Italy (Cottarelli et al. 2012; Bruno et al. 2017), we carried out new campaigns in caves of Calabria (Southern peninsular Italy) and collected new material which we describe and analyse in the present paper, where we aim to: 1) describe and taxonomically define three new species of Parastenocarididae; 2) verify the validity of the genus Cottarellicaris and the possible affinities between Cottarellicaris and the morphologically sister genus Stammericaris, based on both morphological and molecular evidences; 3) provide insights on the genus Proserpinicaris as defined by Karanovic et al. (2012) and discussed by Corgosinho et al. (2012) also based on the development of the P4 endopod in the last copepodid stage of some species of this genus; 4) widen the biogeographic and ecological knowledge of the three genera.

\section{Material and methods}

\section{Site description and sampling methods}

Three of the investigated caves (Grotta superiore di Sant'Angelo, Grotta Vucco Ucciardo, Grotta dello Scoglio) belong to the same hydrogeological system. The fourth cave (Grotta del Banco di ferro) and the last cave (Le Grave complex, lately renamed Grave Grubbo) each belong to a different lithological unit (Fig. 1, supplementary material). Grotta superiore di Sant'Angelo, Grotta Vucco Ucciardo, Grotta dello Scoglio develop in the dolostone hill above the small town of Cassano allo Ionio (Province of Cosenza, Calabria). They occur within a range of about $1 \mathrm{~km}$ (Table 1). The caves are hypogenic, i.e., produced mainly by deep-seated water recharge (see Klimchouk et al. 2017 and references therein), and possibly developed during the Middle Pleistocene (Galdenzi \& Maruoka 2019). The carbonate rock consists of highly fractured Triassic dolostone and Jurassic limestone with gypsum filling (Galdenzi \& Maruoka 2019). Each cave consists of several sub-parallel, horizontal relict passages in overlapping levels. In each cave level, a network of passages develops, generally along sets of parallel fractures and faults. Some include major rooms, formed after the collapse of bedrock partitions between the levels. The replacement gypsum is abundant and was mined in the past. The gypsum deposits form wall crusts and massive floor deposits.

Grotta superiore di Sant'Angelo (Cassano allo Ionio, Cosenza Province, 39 $47^{\prime} 20.24^{\prime \prime}$ N, 16 $16^{\circ} 18^{\prime 25.60^{\prime \prime}}$ E, cadastral number: $\mathrm{Cb}$ 102), opens at $377 \mathrm{~m}$ a.s.l. and is the upper level of a complex of three caves, extending for a total of $3650 \mathrm{~m}$ into Upper Triassic limestone-dolomite. The ceiling above the sampled rimstone pools is about $140 \mathrm{~m}$ thick. The cave is active, water forms small permanent lakes. To collect specimens for this study, on 9 May 2017 the following amounts of water were collected with a syringe 
Table 1. Estimated distances between caves and from the seashore for each cave.

\begin{tabular}{|c|c|c|c|c|c|c|}
\hline & Taxon & $\begin{array}{l}\text { Cottarellicaris } \\
\text { sanctiangeli } \\
\text { sp. nov. }\end{array}$ & $\begin{array}{l}\text { Cottarellicaris } \\
\text { sanctiangeli } \\
\text { sp. nov. }\end{array}$ & $\begin{array}{l}\text { Cottarellicaris } \\
\text { sanctiangeli } \\
\text { sp. nov. }\end{array}$ & $\begin{array}{c}\text { Stammericaris } \\
\text { vincentimariae } \\
\text { sp. nov. }\end{array}$ & $\begin{array}{l}\text { Proserpinicars } \\
\text { specincola } \\
\text { sp. nov. }\end{array}$ \\
\hline & Cave & $\begin{array}{c}\text { Grotta Vucco } \\
\text { Ucciardo }\end{array}$ & $\begin{array}{c}\text { Grotta } \\
\text { superiore di } \\
\text { Sant'Angelo }\end{array}$ & $\begin{array}{c}\text { Grotta del } \\
\text { Banco di ferro }\end{array}$ & $\begin{array}{l}\text { Grotta dello } \\
\text { Scoglio }\end{array}$ & Grave Grubbo \\
\hline \multirow{5}{*}{ 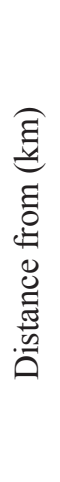 } & Seashore & 16 & 17 & 16 & 17 & 22 \\
\hline & $\begin{array}{l}\text { Grotta superiore } \\
\text { di Sant'Angelo }\end{array}$ & 1.3 & - & - & - & - \\
\hline & $\begin{array}{c}\text { Grotta del } \\
\text { Banco di ferro }\end{array}$ & 7 & 7 & - & - & - \\
\hline & $\begin{array}{l}\text { Grotta dello } \\
\text { Scoglio }\end{array}$ & 1.1 & 0.35 & 7 & - & - \\
\hline & Grave Grubbo & 72 & 72 & 80 & 72 & - \\
\hline
\end{tabular}

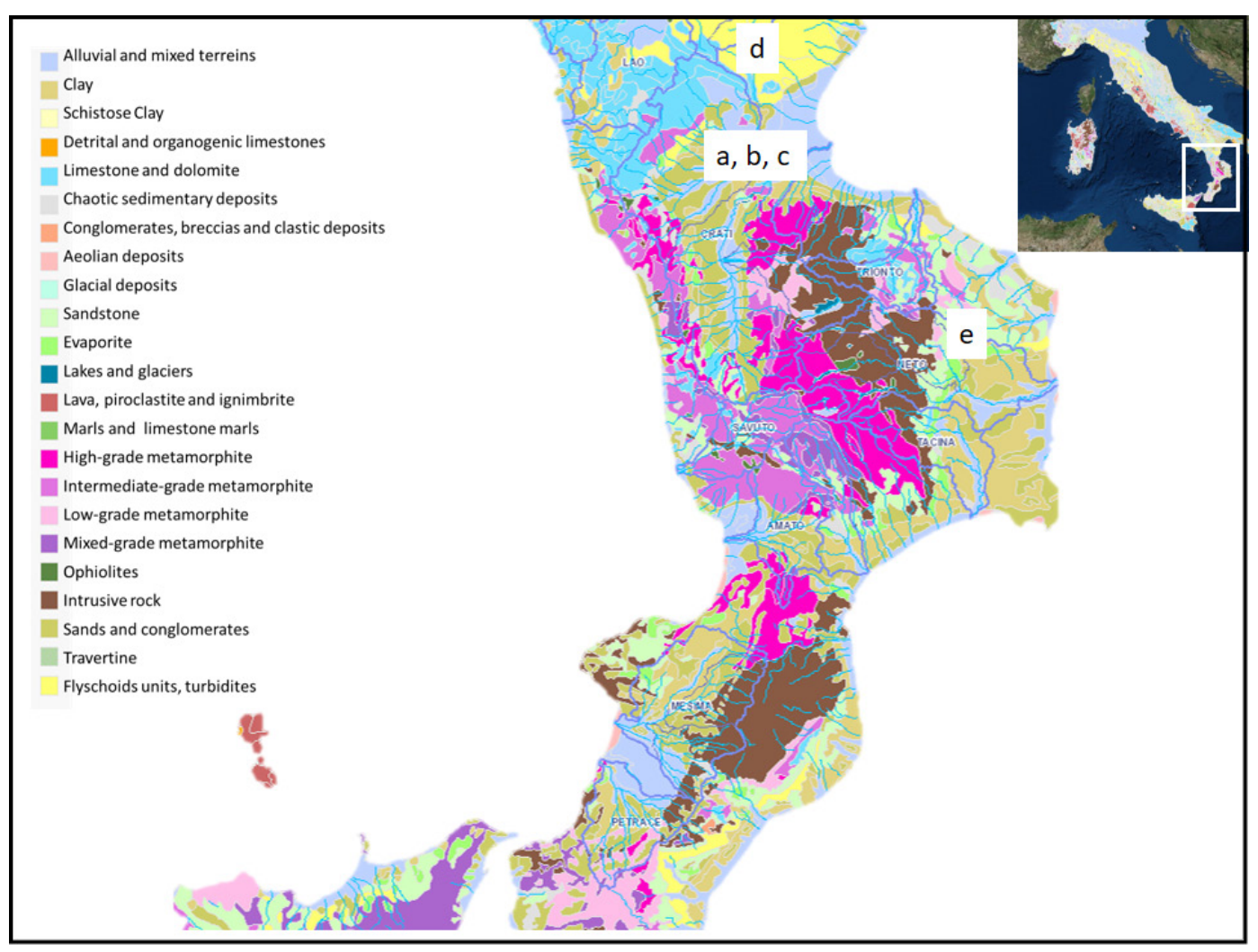

Fig. 1. Location map of the collection sites in Calabria, and lithological units. a. Grotta superiore di Sant'Angelo. b. Grotta Vucco Ucciardo. c. Grotta dello Scoglio. d. Grotta del Banco di ferro. e. Grave Grubbo. 
or with a portable hand pump from four rimstone pools: $3000 \mathrm{~mL}$ (pool 1), $2450 \mathrm{~mL}$ (pool 2), $550 \mathrm{~mL}$ (pool 3), $280 \mathrm{~mL}$ (pool 4). Water samples were preserved in thermal bottles and carried to the laboratory.

Grotta Vucco Ucciardo (Cassano allo Ionio, Cosenza Province, 3947'3.56" N, 16 $16^{\prime} 14.87^{\prime \prime}$ E, cadastral number: $\mathrm{Cb} 118)$ opens at $240 \mathrm{~m}$ a.s.l. and develops for a total of $75 \mathrm{~m}$ (Gasparo 1980); the ceiling above the sampled rimstone pool is about $50 \mathrm{~m}$ thick. The cave is not active, water drips in the upper branch of the cave only during periods of rainfall. Water samples were collected (as above) from three rimstone pools on 25 April 2013 (pool 1, $517 \mathrm{~mL}$ ) and 27 April 2015 (pool 1, $728 \mathrm{~mL}$; pool 2, $515 \mathrm{~mL}$; pool 3, $260 \mathrm{~mL})$.

Grotta dello Scoglio (Cassano allo Ionio, Cosenza Province, 3947'9.38" N, 16 16 18'31.89" E, cadastral number $\mathrm{Cb} 372$ ) is one of the longest caves in Calabria (about $2300 \mathrm{~m}$ total length and $120 \mathrm{~m}$ height) and develops on four levels. It opens at $470 \mathrm{~m}$ a.s.1., the ceiling above the sampled rimstone pools is about $40 \mathrm{~m}$ thick. The cave is active, water forms small permanent lakes and pools. Water samples were collected (as above) from four rimestone pools (pool 1, $1206 \mathrm{~mL}$; pool 2, $603 \mathrm{~mL}$; pool 3, $515 \mathrm{~mL}$; pool 4, $535 \mathrm{~mL}$ ) on 25 April 2015.

Grotta del Banco di ferro (San Lorenzo Bellizzi, Cosenza Province, 3952'26.38" N, 16²0'27.35" E, cadastral number: $\mathrm{Cb} 42$ ) is at about $7 \mathrm{~km}$ distance from the aforementioned group of caves (Table 1). It opens at $977 \mathrm{~m}$ a.s.l. and develops horizontally for about $150 \mathrm{~m}$ in an Upper Cretaceous limestone. The thickness of the ceiling is about $40 \mathrm{~m}$, the cave is fossil and water drips during periods of rainfall or snowmelt. The cave is located in the Pollino National Park. Water samples were collected (as above) from five rimestone pools on 26 April 2013 (pool 1, $750 \mathrm{~mL}$ ), 27 April 2015 (pool 1, $1742 \mathrm{~mL}$; pool 2, $590 \mathrm{~mL}$; pool 3, $231 \mathrm{~mL}$; pool 4, $98 \mathrm{~mL}$ ) and 10 May 2017 (pool 2, $2000 \mathrm{~mL}$; pool 3, $1272 \mathrm{~mL}$; pool 5, $15 \mathrm{~mL})$.

Grave Grubbo (Verzino, Crotone Province, 39 $15^{\prime} 41.4^{\prime \prime} \mathrm{N}, 16^{\circ} 51^{\prime} 45.1^{\prime \prime}$ E, cadastral number: $\mathrm{Cb} 258$ ), opens at $285 \mathrm{~m}$ a.s.l. and extends for $1926 \mathrm{~m}$; the cave belongs to the extensive Le Grave Complex, the second longest system developing in gypsum deposits in Italy. The cave area is about 72 and $80 \mathrm{~km}$ distance from Cassano allo Ionio caves and Grotta del Banco di ferro, respectively (Table 1). The cave develops into Messinian evaporite (Forti \& Sauro 1996); the cave is active and water flows into one of its branches from an inlet point during rainy periods. In the dry seasons, water drops and creates pools in the impermeable clay soil (i.e., the collection sites). A second branch hosts a permanent subterranean stream, with sulfuric water. Water samples were collected (as above) from 12 pools on 28 August 2015 (pool 1, $440 \mathrm{~mL}$; pool 2, $477 \mathrm{~mL}$; pool 3, $537 \mathrm{~mL}$; pool 4, $616 \mathrm{~mL}$; pool 5, $155 \mathrm{~mL}$; pool 6, $515 \mathrm{~mL}$; pool 7, $1019 \mathrm{~mL}$; pool 8, $577 \mathrm{~mL}$; pool 9, $717 \mathrm{~mL}$; pool 10, $587 \mathrm{~mL}$; pool 11, $227 \mathrm{~mL}$; pool 12, $255 \mathrm{~mL}$ ) and 21 April 2018 (pool 3, $2660 \mathrm{~mL}$ ).

\section{Morphological methods}

All specimens were sorted alive under a stereo microscope, placed individually in $70 \%$ or $100 \%$ ethanol and stored refrigerated until further morphological and/or molecular analysis. Before morphological analyses, specimens were rinsed in distilled water, dissected and mounted in Faure's or glycerine jelly medium solution between two cover slips to allow observations from both sides. Illustrations were made at different magnifications up to a maximum of $1250 \times$, using drawing tubes mounted on a Zeiss Axioskop ${ }^{\circledR}$ phase-contrast microscope and a Polyvar Reichert-Jung ${ }^{\circledR}$ interferential-contrast microscope.

The morphology of five females and five males of Cottarellicaris sanctiangeli Bruno \& Cottarelli sp. nov. collected in the type locality was also observed using a JEOL JSM 6010LA scanning electron microscope. The specimens were rehydrated in a graded ethanol series $(90 \%, 70 \%, 50 \%, 30 \%, 10 \%$ at $4^{\circ} \mathrm{C}$ for 10 minutes each step), fixed in gluteraldehyde in cacodylate solution (at $4^{\circ} \mathrm{C}$ for 1 hour), washed 
in cacodylate buffer ( $\mathrm{pH} 7.2,4^{\circ} \mathrm{C}$ for 1 hour), post-fixed in $1 \%$ osmium tetraoxide in the same buffer $\left(4^{\circ} \mathrm{C}\right.$ for 1 hour), washed in cacodylate buffer $\left(\mathrm{pH} 7.2,4^{\circ} \mathrm{C}\right.$ for 1 hour), dehydrated in a graded ethanol series $\left(20 \%, 30 \%, 50 \%, 70 \%, 80 \%, 90 \%, 100 \%\right.$ ethanol at $4^{\circ} \mathrm{C}$ for 10 minutes each step), critical-pointdried in a Balzers Union H CPD 020 apparatus and coated with gold in a Balzers Union HMED 010 sputter coater.

Specimens of the type series are deposited at the Natural History Museum, London (NHMUK). The stubs are deposited at the Interdepartmental Center for Electron Microscopy, Tuscia University (CIME). The taxonomic descriptions and the authority of the new species are the sole responsibility of Bruno (MCB) and Cottarelli (VC). Authorship of the new species should be cited as Bruno \& Cottarelli in Bruno et al. (International Commission on Zoological Nomenclature, 1999, Recommendation 51E).

\section{Abbreviations}

$\begin{array}{ll}\mathrm{A} 1 & =\text { antennules } \\ \mathrm{A} 2 & =\text { antenna } \\ \mathrm{Ae} & =\text { aesthetasc } \\ \mathrm{Enp} & =\text { endopod } \\ \mathrm{Exp} & =\text { exopod } \\ \mathrm{Mdb} & =\text { mandible } \\ \mathrm{Mx} 1 & =\text { maxillule } \\ \mathrm{Mx} 2 & =\text { maxilla } \\ \mathrm{Mxp} & =\text { maxilliped } \\ \mathrm{P} 1-\mathrm{P} 5 & =\text { first to fifth pereiopod } \\ \mathrm{P} 6 & =\text { rudimentary sixth pereiopod }\end{array}$

The nomenclature and descriptive terminology follow Huys \& Boxshall (1991), terminology and homologisation of maxillary and maxillipedal structures follow Ferrari \& Ivanenko (2008).

\section{Single-specimen DNA extraction, PCR amplification and sequencing}

Following the multi-gene approach used in a previous analysis of Parastenocarididae phylogenetic relationships (Bruno et al. 2017), we used one mitochondrial (cytochrome C oxidase subunit 1 gene, COI) and one nuclear (18S rDNA) gene for our analyses. We focused our phylogenetic analysis on the seven following species of Parastenocarididae: $C$. sanctiangeli Bruno \& Cottarelli sp. nov., S. vincentimariae Bruno \& Cottarelli sp. nov., S. trinacriae, S. diversitatis, S. pasquinii, S. destillans and P. amalasuntae. We use as outgrops two species belonging to different families, i.e., Bereraia sp. (family Leptopontiidae Lang, 1948) and Bryocamptus (Rheocamptus) stillae Cottarelli \& Bruno, 2012 (family Canthocamptidae Brady, 1880). All the species used for the analyses were collected in Italy (Table 2). Proserpinicaris specincola Bruno \& Cottarelli sp. nov. was not included in the analysis because only four specimens were collected overall and these were used for the morphological analysis. To provide a better definition of the phylogenetic relationships between and within Cottarellicaris and Proserpinicaris, two of us (VC and MCB) conducted supplementary sampling campaigns in Sardinia and peninsular Italy in 2016, 2017 and 2018, aiming at collecting further specimens of known species belonging to these two genera. Unexpectedly, we were not able to find any parastenocaridid, even in sites known in the past for the abundance of their populations. The causes of their absence are difficult to determine, but are possibly related to the very dry periods recorded in the last few years in the collecting areas, which caused severe droughts in running water bodies, and/or to the diffuse pollution affecting the volcanic lakes in Latium (Central Italy).

For the molecular analysis, twenty-three specimens of C. sanctiangeli Bruno \& Cottarelli sp. nov. (10 from Grotta superiore di Sant'Angelo, 10 from Grotta Vucco Ucciardo and 3 from Grotta del Banco di ferro) and eleven specimens of $S$. vincentimariae Bruno \& Cottarelli sp. nov., were identified 
BRUNO M.C. et al., New Parastenocarididae (Copepoda, Harpacticoida) from Southern Italy

Table 2. List of species used for phylogenetic analysis, collection site, number of specimens for which DNA was successfully extracted and amplified for the two investigated fragments (COI and 18S), number of haplotypes recorded for each species/fragment, and GenBank accession numbers.

\begin{tabular}{|c|c|c|c|c|}
\hline Species & Collection site & $\begin{array}{l}\text { COI: N ind./ } \\
\text { haplotypes (names) } \\
\text { sequenced, GenBank } \\
\text { acc. numbers }\end{array}$ & $\begin{array}{l}\text { 18S: } N \text { ind./ } \\
\text { haplotypes } \\
\text { sequenced, } \\
\text { GenBank acc. } \\
\text { numbers }\end{array}$ & Published in \\
\hline Bereraia sp. & $\begin{array}{l}\text { Belice River } \\
\text { (Porto Palo, } \\
\text { Agrigento, Sicily) }\end{array}$ & $\begin{array}{l}\text { 3/3 (a,b, c) } \\
\text { Haplo_a: MF462061 } \\
\text { Haplo_b: MF462062 } \\
\text { Haplo_c: MF462063 }\end{array}$ & $\begin{array}{l}2 / 1 \\
\text { MF462052 }\end{array}$ & $\begin{array}{l}\text { Bruno et al., } \\
2017\end{array}$ \\
\hline $\begin{array}{l}\text { Bryocamptus } \\
\text { (Rheocamptus) } \\
\text { stillae }\end{array}$ & $\begin{array}{l}\text { Grotta Conza } \\
\text { (Palermo, Sicily) }\end{array}$ & $\begin{array}{l}2 / 1 \\
\text { MF462064 }\end{array}$ & $\begin{array}{l}2 / 1 \\
\text { MF462053 }\end{array}$ & $\begin{array}{l}\text { Bruno et al., } \\
2017\end{array}$ \\
\hline $\begin{array}{l}\text { Cottarellicaris } \\
\text { sanctiangeli } \\
\text { sp. nov. }\end{array}$ & $\begin{array}{l}\text { Grotta superiore } \\
\text { di Sant'Angelo; } \\
\text { Vucco Ucciardo; } \\
\text { Grotta del Banco } \\
\text { di ferro }\end{array}$ & $\begin{array}{l}\text { 22/2 } \\
\text { Haplo_a: MN937321 } \\
\text { Haplo_b: MN937340 }\end{array}$ & $\begin{array}{l}22 / 1 \\
\text { MN959799- } \\
\text { MN959820 }\end{array}$ & Present work \\
\hline $\begin{array}{l}\text { Stammericaris } \\
\text { vincentimariae } \\
\text { sp. nov. }\end{array}$ & $\begin{array}{l}\text { Grotta dello } \\
\text { Scoglio }\end{array}$ & $\begin{array}{l}\text { 5/2 } \\
\text { Haplo_a: MN937343- } \\
\text { Haplo_b: MN937345 }\end{array}$ & $\begin{array}{l}\text { 5/1 } \\
\text { MN959821- } \\
\text { MN959825 }\end{array}$ & Present work \\
\hline $\begin{array}{l}\text { Stammericaris } \\
\text { diversitatis }\end{array}$ & $\begin{array}{l}\text { Grotta Conza } \\
\text { (Palermo, Sicily) }\end{array}$ & $\begin{array}{l}\text { 2/1 } \\
\text { MF462067 }\end{array}$ & $\begin{array}{l}2 / 1 \\
\text { MF462057 }\end{array}$ & $\begin{array}{l}\text { Bruno et al., } \\
2017\end{array}$ \\
\hline $\begin{array}{l}\text { Stammericaris } \\
\text { trinacriae }\end{array}$ & $\begin{array}{l}\text { Grotta di Entella } \\
\text { (Palermo, Sicily) }\end{array}$ & $\begin{array}{l}\text { 11/3 (a, b, c) } \\
\text { Haplo_a: MF462069 } \\
\text { Haplo_b: MF462070 } \\
\text { Haplo_c: MF462071 }\end{array}$ & $\begin{array}{l}\text { 2/2 (a,b) } \\
\text { haplo_a: MF } 462059 \\
\text { haplo_b: MF462060 }\end{array}$ & $\begin{array}{l}\text { Bruno et al., } \\
2017\end{array}$ \\
\hline $\begin{array}{l}\text { Stammericaris } \\
\text { destillans }\end{array}$ & $\begin{array}{l}\text { Grotta della } \\
\text { Molara (Palermo, } \\
\text { Sicily) }\end{array}$ & $\begin{array}{l}\text { 14/1 } \\
\text { MF462066 }\end{array}$ & $\begin{array}{l}\text { 2/1 } \\
\text { MF462056 }\end{array}$ & $\begin{array}{l}\text { Bruno et al., } \\
2017\end{array}$ \\
\hline $\begin{array}{l}\text { Stammericaris } \\
\text { pasquinii }\end{array}$ & $\begin{array}{l}\text { Bolsena Lake } \\
\text { (Viterbo, Latium) }\end{array}$ & $\begin{array}{l}12 / 1 \\
\text { MF462068 }\end{array}$ & $\begin{array}{l}3 / 1 \\
\text { MF462058 }\end{array}$ & $\begin{array}{l}\text { Bruno et al., } \\
2017\end{array}$ \\
\hline $\begin{array}{l}\text { Proserpinicaris } \\
\text { amalasuntae }\end{array}$ & $\begin{array}{l}\text { Bolsena Lake } \\
\text { (Viterbo, Latium) }\end{array}$ & $\begin{array}{l}11 / 1 \\
\text { MF462065 }\end{array}$ & $\begin{array}{l}\text { 6/2 (a,b) } \\
\text { haplo_a: MF462054 } \\
\text { haplo_b: MF462055 }\end{array}$ & $\begin{array}{l}\text { Bruno et al., } \\
2017\end{array}$ \\
\hline
\end{tabular}

morphologically without dissection under a $100 \times$ magnification using a MOTIC SMZ-168 stereoscope and stored individually in $100 \%$ ethanol at $-20^{\circ} \mathrm{C}$ until DNA extraction. Specimens of the seven remaining species have been sequenced in a previous work (Bruno et al. 2017) and their sequences were retrieved from GenBank. Prior to DNA extraction, ethanol preserved samples of the two new species 
were rehydrated and rinsed 10 times with MilliQ water. The QIAamp DNA Investigator kit (QIAGEN, Hilden, Germany) was used for whole DNA extraction following the specific protocol 'Isolation of Total DNA from Tissue'. COI gene was amplified using the LCO1490 e HCO2198 primers (Folmer et al. 1994) producing a fragment of $711 \mathrm{bp} .18 \mathrm{~S}$ rRNA was amplified using the 18 SFnew and $9 \mathrm{r}$ primers (Tang et al. 2012) producing a fragment of $2065 \mathrm{bp}$ or $2370 \mathrm{bp}$. Amplifications were carried out with a Professional Trio Thermocycler (Biometra) in $25 \mu 1$ volumes containing $4 \mu 1 \mathrm{DNA}, 2.5 \mathrm{mM} \mathrm{MgCl} 2$, $0.8 \mathrm{mM}$ dNTPs, 10x PCR buffer, $0.8 \mu \mathrm{mol}$ of each primer and 1.25 U of AmpliTaq Gold (Thermo Fisher Scientific, US).

PCR cycles consisted of initial denaturation at $95^{\circ} \mathrm{C}$ for $10 \mathrm{~min}$, followed by 35 cycles of denaturation at $95^{\circ} \mathrm{C}$ for $45 \mathrm{~s}$, annealing at $55^{\circ} \mathrm{C}$ for $40 \mathrm{~s}$, extension at $72^{\circ} \mathrm{C}$ for 2 minutes and a final extension at $72^{\circ} \mathrm{C}$ for 7 minutes. The PCR product was purified using the CleanNGS (Voden) and sequenced using the Brilliant Dye Terminator Cycle sequencing kit (Nimagen). Sequencing was carried out using the 3730xl DNA Analyzer (Thermo Fisher Scientific, US). Extraction and sequencing were performed at the Sequencing and Genotyping Platform, Research and Innovation Centre, Fondazione Edmund Mach (San Michele all'Adige, Italy).

\section{Phylogenetic analysis}

The quality of the obtained chromatograms was measured with their Phred scores (Richterich 1998). Only those sequences with continuous reads of high-quality bases $(\mathrm{QV}>20)$ were retained. When the quality of the forward sequences was not adequate, we additionally obtained the complement/reverse sequences. Sequences were analysed and manually proofread with the software Chromas ver. 2.6.2 (Technelysium, Pty. Ltd. 1998, Queensland, Australia) and aligned with ClustalX ver. 2.1 (Larkin et al. 2007).

In order to investigate the pattern of molecular diversity of the two genera Cottarellicaris and Stammericaris, the sequences of Stammericaris available on GenBank were included in the analyses in addition to the novel sequences produced in the frame of this study. Accordingly, mitochondrial and nuclear sequences of one specimen of $S$. pasquinii, one specimen of $S$. destillans, one specimen of S. diversitatis and three specimens of $S$. trinacriae were downloaded from GenBank and included in the analyses (see Table 2 for their accession numbers). No sequences of Cottarellicaris were available in public repositories. Mitochondrial and nuclear sequences of Proserpinicaris amalasuntae, Bryocamptus (Rheocamptus) stillae and Bereraia sp. were downloaded from GenBank to be included in the analysis (see Table 2 for their accession numbers).

The incongruence length difference test (ILD; Farris et al. 1995) as implemented in PAUP* ver. 4.0b10 (Swofford 2003) was used to test whether the mitochondrial and nuclear fragments could be combined into one dataset. According to Cunningham (1997), if $\mathrm{P}>0.01$, pooling the data improves the phylogenetic accuracy and thus it is admissible to merge the tested datasets into a single matrix. With $\mathrm{P}=0.86$ this condition was fulfilled, and the mtDNA COI and nuDNA $18 \mathrm{~S}$ datasets were analysed jointly. In addition, in order to account for the different best-fit evolutionary models suggested for the mitochondrial and nuclear DNA markers, the combined dataset was partitioned and the most appropriate model of sequence evolution was imposed for each partition. Partition Finder ver. 1.0.1 (Lanfear et al. 2012) according to the Akaike information criterion (AIC; Akaike 1974) was used to chose the best evolutionary model for each partition. Phylogenetic analyses were performed setting independent models of nucleotide evolution for the 'COI' partition (Hasegawa-Kishino-Yano model of evolution with a proportion of invariable sites and gamma-distributed rate variation among sites, $\mathrm{HKY}+\Gamma+\mathrm{I})$ and for the ' $18 \mathrm{~S}$ ' partition (General Time Reversible model of evolution with a proportion of invariable sites, GTR + I). For the combined DNA dataset, Bayesian inference of phylogeny (BI) and Maximum likelihood analysis (ML) were performed as implemented in MrBayes ver. 3.2.6 (Ronquist et al. 2012) and PhyMl ver. 3 (Guindon \& Gascuel 
2003) software packages. As a measure of branch support, bootstrap values (Felsenstein 1985) were calculated with 1000 replicates in the ML tree, and posterior probability values were reported on the BI tree. In the BI analyses, four independent Markov chain Monte Carlo (MCMC) analyses were run with 1 million generations (temp.: 0.2 ; default priors). Trees and parameter values were sampled every 100 generations, resulting in 10000 saved trees per analysis, the convergence of each run was calculated by requiring a value of effective sample size above 200; node support estimates were calculated after discarding the first $20 \%$ of the trees as 'burn-in'.

Following Karanovic \& Cooper (2011b), average mtDNA COI sequence divergence between parastenocaridid species was estimated with MEGA X (Kumar et al. 2018) based on uncorrected $p$-distance.

\section{Results}

\section{Taxonomy}

Subclass Copepoda H. Milne Edwards, 1840

Order Harpacticoida G.O. Sars, 1903

Family Parastenocarididae Chappuis, 1940

Subfamily Parastenocaridinae Chappuis, 1940

Genus Cottarellicaris Schminke, 2013

Cottarellicaris sanctiangeli Bruno \& Cottarelli sp. nov. urn:1sid:zoobank.org:act:BFD63C80-116A-49C7-B10D-547D0146CB5A

Figs 2-8; Tables 1-3

\section{Diagnosis}

Cottarellicaris sanctiangeli Bruno \& Cottarelli sp. nov. is characterized by the peculiar morphology of the male P4 enp, with apically curved inner tip and, mainly, with a thin proximal outgrowth as long as the apical (crenulate) lamellar outgrowth. Females are characterized by the P3 enp being shorter than the corresponding exp-1.

\section{Etymology}

The species epithet is the masculine genitive of the Latin words 'sanctus' and 'angelus', meaning 'Saint' and 'angel', respectively, and refer to the locus typicus of this Cottarellicaris, i.e., a cave dedicated to Saint Michael the Archangel, whose cult is widespread in Southern Italy.

\section{Material examined}

\section{Holotype}

ITALY $\bullet{ }^{\top}$; Cosenza Province, Cassano allo Ionio, Complesso Grotte di Sant'Angelo, Grotta Superiore di Sant'Angelo, pool 2; approximate coordinates 39 47'20.24" N, 16²18'25.60" E; 9 May 2017; R. Grasso and M.T. Spena leg.; dissected and mounted on one slide labelled "Cottarellicaris sanctiangeli holotype: male"; NHMUK 2020.4.

\section{Paratypes}

ITALY $\bullet 2 \hat{\partial} \bar{\partial}$; same collection data as for holotype; each dissected and mounted on one slide labelled "Cottarellicaris sanctiangeli paratype: male"; NHMUK 2020.5 to $2020.6 \cdot 2$ ôं; same collection data as for holotype but pool 4; dissected and mounted each on one slide labelled "Cottarellicaris sanctiangeli paratype: male"; NHMUK 2020.7 to 2020.8 • 1 ते; same collection data as for holotype but pool 4; undissected and mounted on one slide labelled "Cottarellicaris sanctiangeli paratype: male"; NHMUK 2020.9 • 3 우; same collection data as for holotype; each dissected and mounted on one 
slide labelled "Cottarellicaris sanctiangeli paratype: female"; NHMUK 2020.10 to 2020.12 • 1 q; same collection data as for holotype; mounted on one slide labelled "Cottarellicaris sanctiangeli paratype: female"; NHMUK 2020.13 • 1 q; same collection data as for holotype but pool 4; dissected and mounted on one slide labelled "Cottarellicaris sanctiangeli paratype: female"; NHMUK 2020.14 • 1 क; same collection data as for holotype but pool 4; mounted on one slide labelled "Cottarellicaris sanctiangeli paratype: female"; NHMUK 2020.15.

\section{Other material}

ITALY 1 đ; Cosenza Province, Cassano allo Ionio, Vucco Ucciardo, pool 1; approximate coordinates; $39^{\circ} 47^{\prime} 3.56^{\prime \prime}$ N, 16 $6^{\circ} 19^{\prime} 14.87^{\prime \prime}$ E; 25 Apr. 2013; R. Grasso and M.T. Spena leg.; mounted on one slide labelled "Cottarellicaris sanctiangeli: male"; NHMUK 2020.16 • $4 \hat{\partial} \widehat{\jmath}$; same collection data as for preceding; each dissected and mounted on one slide labelled "Cottarellicaris sanctiangeli: male"; NHMUK 2020.17 to 2020.20 - 1 क; same collection data as for preceding; mounted on one slide labelled "Cottarellicaris sanctiangeli: female"; NHMUK 2020.21 • 4 우; same collection data as for preceding; each dissected and mounted on one slide labelled "Cottarellicaris sanctiangeli: female";

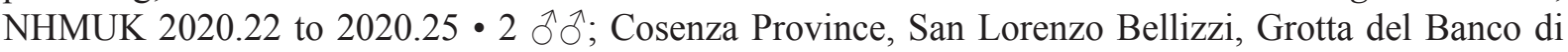
ferro, pool 3; approximate coordinates: 39 $52^{\prime} 26.38^{\prime \prime} \mathrm{N}, 1^{\circ} 20^{\prime} 27.35^{\prime \prime}$ E; 27 May 2015; Grasso and M.T. Spena leg.; each dissected and mounted on one slide labelled "Cottarellicaris sanctiangeli: male"; NHMUK 2020.26 to $2020.27 \cdot 1 \hat{\partial}, 1$ \&; same collection data as for preceding; mounted on one slide labelled "Cottarellicaris sanctiangeli: male and female"; NHMUK 2020.28 to $2020.29 \bullet 2$ ○ , same collection data as for preceding; each dissected and mounted on one slide labelled "Cottarellicaris sanctiangeli: female"; NHMUK 2020.30 to 2020.31 - 1 क , same collection data as for preceding; 10 May 2017; mounted on slide labelled "Cottarellicaris sanctiangeli: female"; NHMUK 2020.32.

\section{Description}

\section{Adult male}

BoDy. Unpigmented, nauplius eye absent. Total body length, measured from tip of rostrum to posterior margin of caudal rami (excluding caudal setae) from 295 to $333 \mu \mathrm{m}$, mean $311 \mu \mathrm{m}(\mathrm{n}=6)$. Habitus (Fig. 2a) cylindrical and slender, without any demarcation between prosome and urosome; prosome to urosome ratio: 0.90 . Free pedigerous somites without any lateral or dorsal expansions, all connected by well-developed arthrodial membranes. Integument weakly sclerotized, without cuticular pits, ornamented with sensilla on all somites except preanal one. Cuticular windows on urosomites and cephalothorax not observed. Cephalothorax representing about $20 \%$ of total body length. Anal somite (Fig. 3a, c) with pair of large dorsal sensilla at base of anal operculum, pair of cuticular lateral pores (one pore on each side) on proximal margin. Anal operculum (Fig. 3a, c) well-developed, ornamented with row of spinules on outer surface, with straight distal margin. Anal sinus wide open.

CAUdAL RAMi (Fig. 3a, c). Shorter than anal somite, approximately cylindrical, slightly divergent; length to width ratio: 2.7. Anterolateral accessory seta (I) and anterolateral seta (II) subequal in length, both setae inserted together distally at $5 / 6$ length of caudal ramus, smooth. Posterolateral seta (III) missing. Outer terminal seta (IV) long and pinnate (length seta/length caudal ramus: 1.5), inserted subterminally and projecting outwards; inner terminal seta (V) without fracture plane. Terminal accessory seta (VI) short (length seta/length caudal ramus: 0.7) and smooth. Dorsal seta (VII) articulate, inserted distally at $5 / 6$ length of the caudal ramus, smooth.

Rostrum (Fig. 4a-b). Small, not demarcated at base, almost reaching distal margin of first antennulary segment, ornamented with two dorsal sensilla.

A1 (Fig. 4a-c). Prehensile, eight-segmented pocket-knife type sensu Schminke (2010). First segment short with transversal row of spinules; second segment longest, with six setae, longest seta unipinnate; third segment with four distal bare setae; fourth segment reduced to a small sclerite with two short setae; 
fifth segment enlarged with inner round expansion carrying one short and two longer subequal setae, and distal tubercle with one seta and one large aesthetasc, reaching past end of eighth segment; sixth segment bare, partially fused to previous one; seventh segment bare, distal anterior corner protruding as curved apophysis ending in bilobate tip; eighth segment with seven setae and apical acrothek represented two

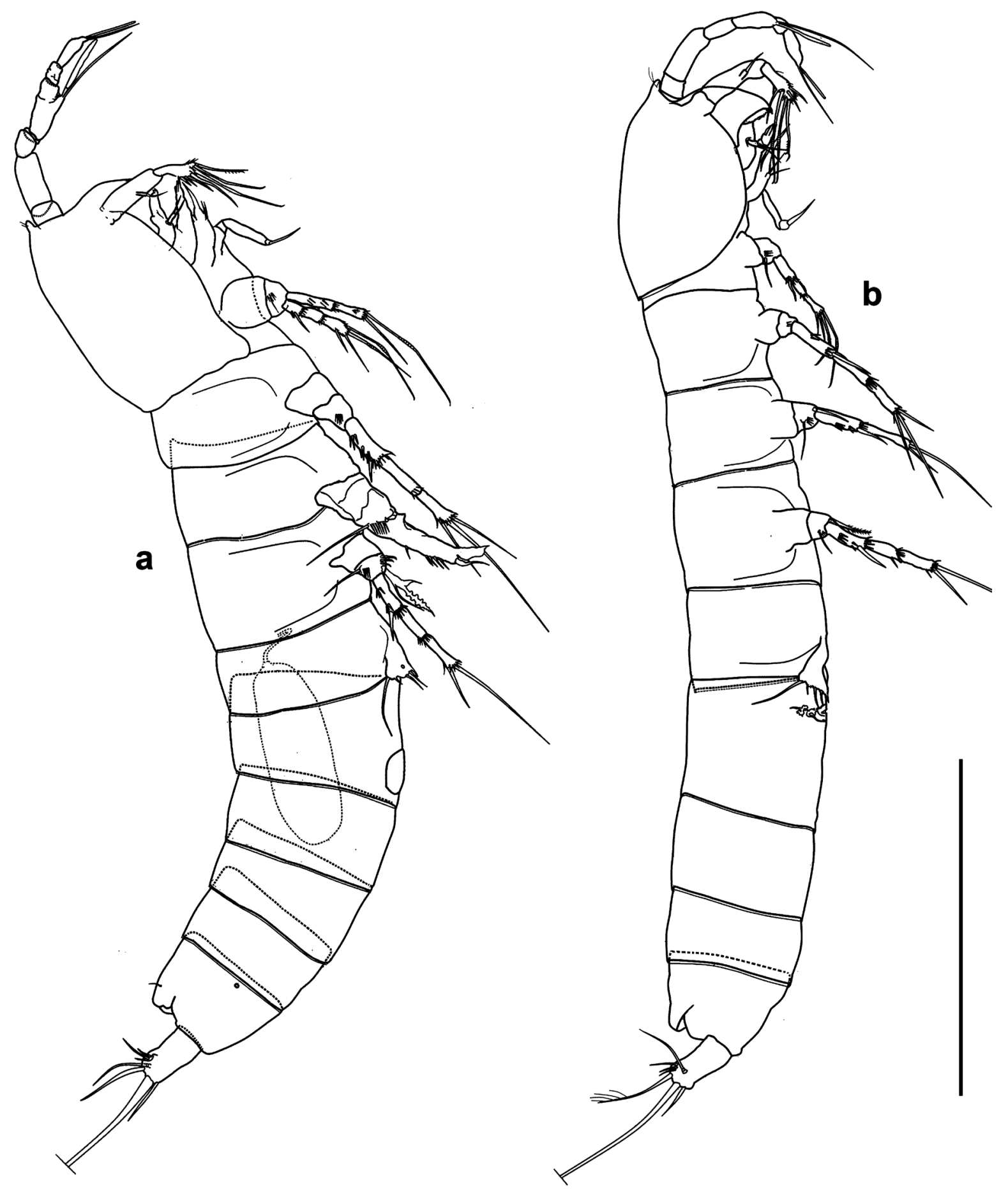

Fig. 2. Cottarellicaris sanctiangeli Bruno \& Cottarelli sp. nov. from Grotta superiore di Sant'Angelo (NHMUK). a. ${ }^{\curvearrowright}$, habitus. b. $\circ$, habitus. Scale bar: $50 \mu \mathrm{m}$. 


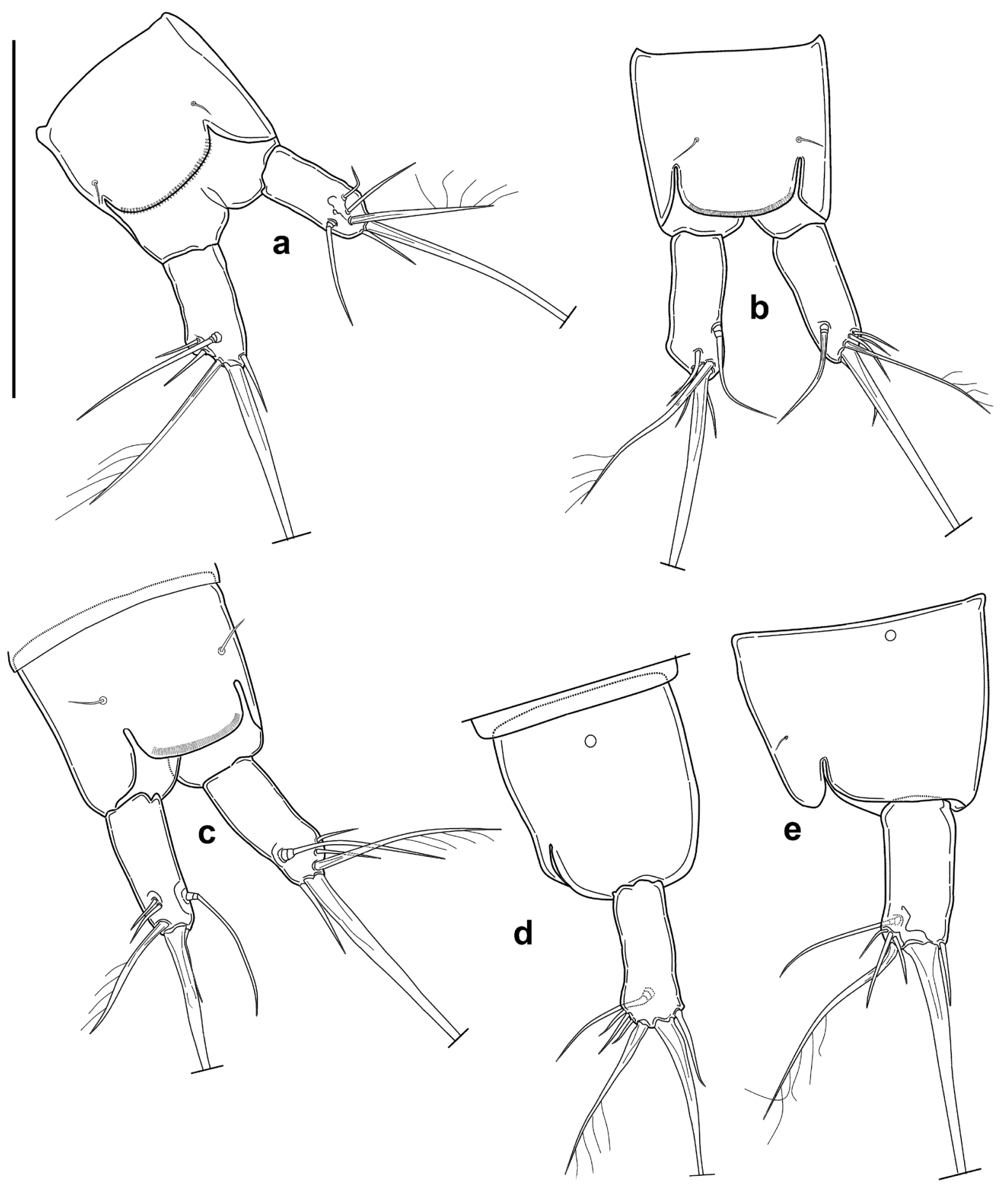

Fig. 3. Cottarellicaris sanctiangeli Bruno \& Cottarelli sp. nov., ô (NHMUK). a. Anal somite, anal operculum and caudal rami, dorsal view. b. Anal somite, anal operculum and caudal rami, dorsal view (variability). c. Anal somite, anal operculum and caudal rami, dorsal view. d. Anal somite, anal operculum and caudal rami, lateral view (variability). e. Anal somite, anal operculum and caudal rami, lateral view (variability). a: Grotta superiore di Sant'Angelo; b, d: Grotta del Banco di ferro; c, e: Grotta Vucco Ucciardo. Scale bar: $50 \mu \mathrm{m}$. 
setae and long, slender aesthetasc. Armature formula: 1-[0], 2-[1 unipinnate +5 bare], 3-[4 bare], 4-[2 bare], 5-[4 bare + ae], 6-[0], 7-[0], 8-[7 bare + $(2$ bare + ae $)]$.

A2 (Fig. 4d). Coxa unarmed; allobasis with transverse row of spinules on inner margin. Exp represented by small segment merged with allobasis, with pinnate apical seta. Enp bearing two short subdistal unipinnate spines and five longer distal elements: two of them geniculated, one transformed with furcate tip, all elements unipinnate, with long spinules near their insertions.

MDB (Fig. 4e). Coxal gnathobase bare, cutting edge with apical teeth and short bipinnate seta. Onesegmented palp, with two smooth, apical setae of equal length.

Mx1 (Fig. 4f). Praecoxal arthrite with three apical curved robust spines apically denticled, one subdistal curved seta. Coxal endite long, with one apical seta. Basis cylindrical, with two distal bare setae. Enp and exp absent (fused to basis without trace).

Mx2 (Fig. 4g). Basis with two endites, proximal endite short, with one thin, bare seta; distal endite cylindrical, longer, armed apically with two subequal thin bare setae and one transformed, leaf-like

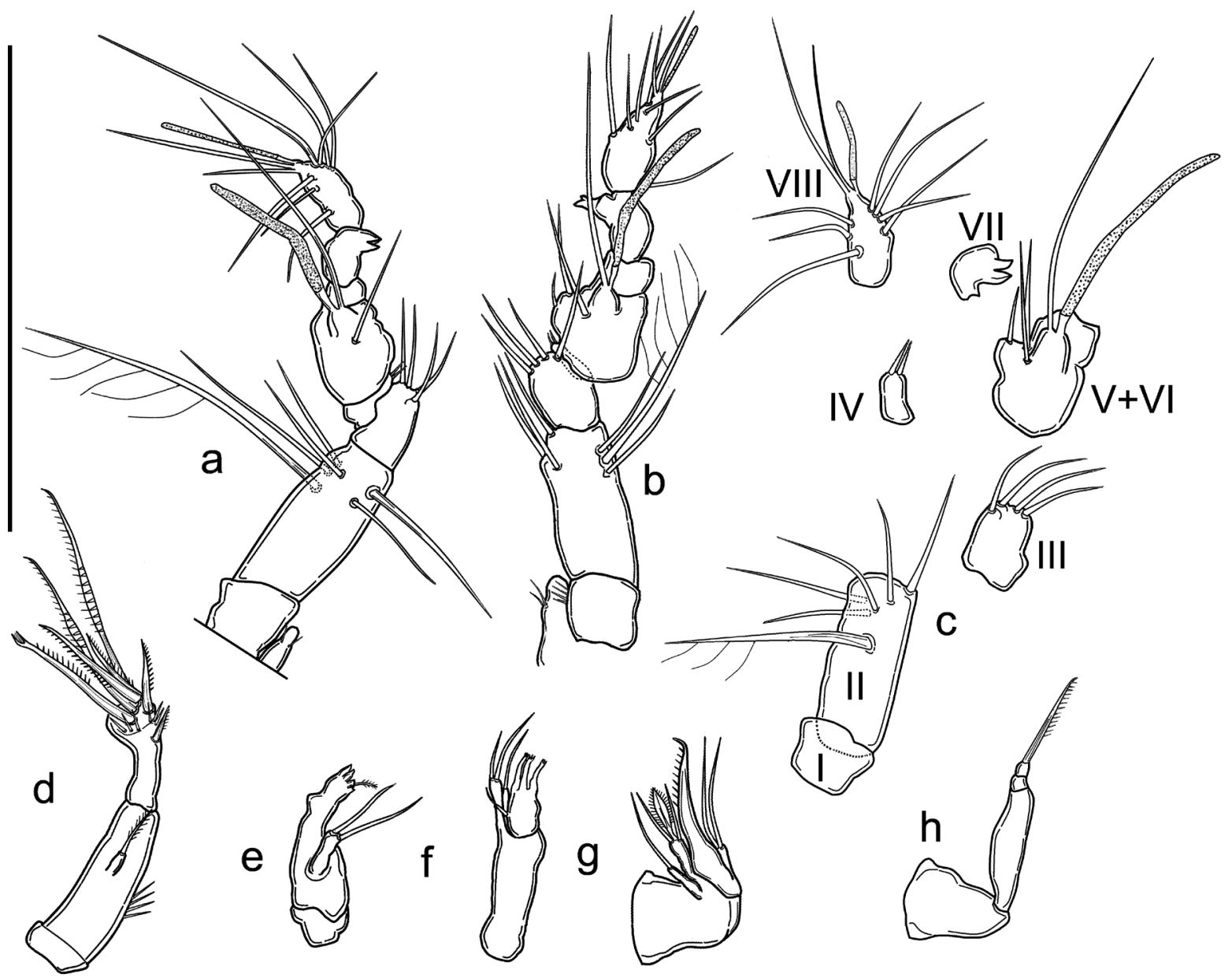

Fig. 4. Cottarellicaris sanctiangeli Bruno \& Cottarelli sp. nov., đ̊ (NHMUK). a. Rostrum and A1, ventral view. b. Rostrum and A1, ventral view. c. A1, disarticulated (antennular segments marked with Roman numerals). d. A2. e. Mdb. f. Mx1. g. Mx2. h. Mxp. a, e-g: Grotta Vucco Ucciardo; b-d, h: Grotta superiore di Sant'Angelo. Scale bar: $50 \mu \mathrm{m}$. 
pinnate seta; proximal endopodal segment drawn into apical unipinnate claw; distal endopodal segment with two long setae of equal length.

Mxp (Fig. 4h). Subchelate, composed of small and unarmed syncoxa, basis slim and elongate, unarmed, 1 -segmented enp fused to the claw-like apical seta.

P1 (Fig. 5a-b). With smooth and small intercoxal sclerite; coxa bare. Basis large, armed with small seta and lamellar hook with rounded tip on the inner margin near the enp insertion. Exp three-segmented, slightly shorter than endopod; exp-1 with thin pinnate seta on outer distal corner; exp-2 shortest and unarmed, ornamented with row of spinules along the subdistal and distal margins; exp-3 with two geniculate unipinnate apical setae and two subapical unipinnate setae. Enp two-segmented; enp-1 as long as first two segments of corresponding exp, with two transversal rows of few spinules on outer margin. Enp-2 thinner and shorter than enp-1, with two spinules at $2 / 3$ of inner margin and spinules along distal margin, with long, geniculate unipinnate seta and shorter unipinnate seta apically.

P2 (Fig. 5c). With smooth intercoxal sclerite, twice as wide as long, with concave distal margin. Coxa bare. Basis unarmed, with row of five spinules on outer margin. Exp three-segmented, exp-1 longest, with row of two spinules at $1 / 3$ of outer margin, longitudinal row of three spinules proximal to strong distolateral unipinnate spine. Second and third segments of same length; exp-2 unarmed, with row of spinules on distolateral corner, exp-3 armed with subapical outer unipinnate spine, apical bipinnate seta and outer unipinnate spine, ornamented with subapical spinule and inner hyaline frill. Enp onesegmented, about half length of exp-1, represented by cylindrical segment, with apical seta about as long as segment and three short spinules.

P3 (Fig. 5d). Intercoxal sclerite small, trapezoidal, unornamented, with slightly concave distal margin. Coxa bare. Basis robust, with long, slender, smooth outer seta and transverse spinule row above, and distal pore. Enp reduced to short seta. Exp-1 of characteristic shape: inner margin with large knob at $1 / 2$ length and basal thin and pointed tubercle fused to exp; outer margin with proximal and distal rows of respectively one and four spinules. Exp-2 fused with exp-1, without ornamentation, prolonged into long apophysis slightly bent inwards, with pointed tip. Distal thumb represented by thin and pointed sigmoid segment, reaching past apophysis.

P4 (Fig. 5f-h). Intercoxal sclerite smaller than in P1-P3, with concave, smooth distal margin. Coxa bare. Basis armed with single slender seta on outer margin; ornamented with row of spinules at base of outer seta; row of three spiniform processes aligned along inner margin, of increasing size from outermost to innermost, all slightly curved inwards. Exp three-segmented, slender, all segments approximately of the same length; exp-1 slightly curved inwards, with distolateral pinnate spine, transversal spinular row at midlength of outer margin, spinular row at distolateral spine insertion, spinular row along distal margin; exp-2 unarmed, with spinular row along distal margin; exp-3 armed with outer unipinnate spine with spinules near insertion and very long apical pinnate seta, spine length less than $1 / 3$ of seta length; ornamentation represented by row of apical spinules and hyaline frill on inner distal corner. Enp onesegmented, as long as first two segments of corresponding exp, represented by curved plate with pointed inner tip carrying at outer border two outgrowths, distal one being elongate lamella, with undulating (crenulate) margins, reaching past end of enp, proximal outgrowth short curved lamella ending in thin tip.

P5 (Fig. 6a-d). Fused to intercoxal sclerite; represented by two trapezoidal cuticular plates with long basipodal seta and small pore near insertion. Armature on free distal margin, from inner to outer: one spiniform seta, three bare setae, outermost very short, remaining two subequal.

P6 (Fig. 6a). Vestigial, fused into simple cuticular plate, unornamented and unarmed. 

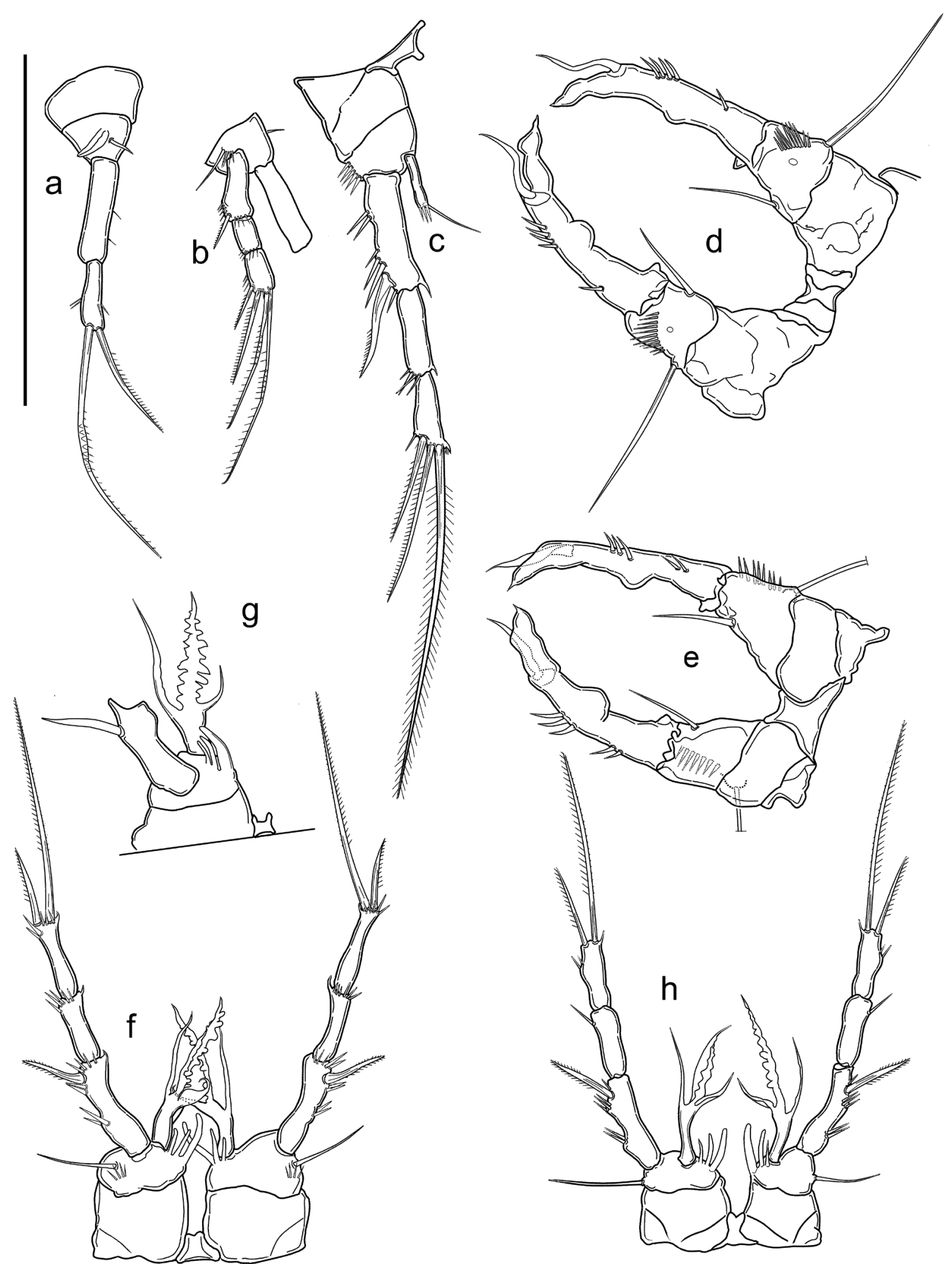

Fig. 5. Cottarellicaris sanctiangeli Bruno \& Cottarelli sp. nov., đ̊ (NHMUK). a. P1, coxa, basis and enp, inner view. b. P1, basis and exp, outer view. c. P2, posterior view. d. P3, anterior view. e. P3, posterior view (variability). f. P4, anterior view. g. P4, intercoxal sclerite, coxa, basis and enp, outer view. h. P4, posterior view. a, c, e, g: Grotta Vucco Ucciardo; b, h: Grotta del Banco di ferro; d, f: Grotta superiore di Sant'Angelo. Scale bar: $50 \mu \mathrm{m}$. 


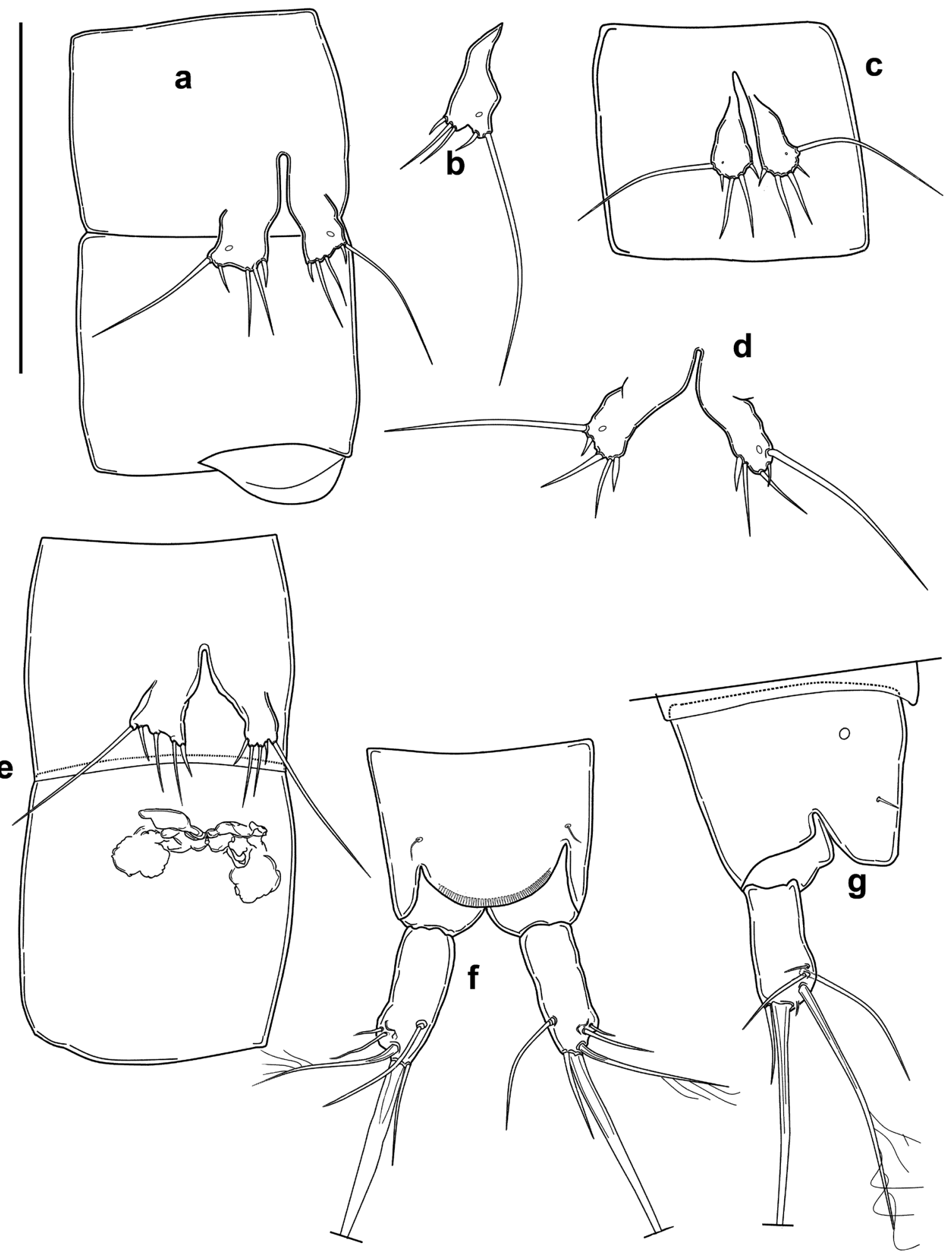

Fig. 6. Cottarellicaris sanctiangeli Bruno \& Cottarelli sp. nov. (NHMUK). a. $\hat{\jmath}, \mathrm{P} 5, \mathrm{P} 6$, first and

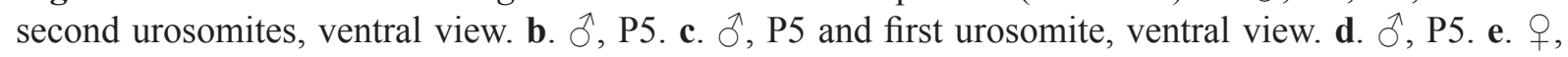
first urosomite, P5, P6, genital double-somite and genital field, ventral view. f. $q$, anal somite, anal operculum and caudal rami, dorsal view. g. + , anal somite, anal operculum and caudal rami, lateral view. a-b, e, g: Grotta Vucco Ucciardo; c: Grotta del Banco di ferro; d, f: Grotta superiore di Sant'Angelo. Scale bar: $50 \mu \mathrm{m}$. 


\begin{abstract}
Adult female
Habitus (Fig. 2b). Cylindrical and slender, without any demarcation between prosome and urosome. Free pedigerous somites without any lateral or dorsal expansions, all connected by well-developed arthrodial membranes. Integument weakly sclerotized, without cuticular pits, ornamented with sensilla on all somites except preanal one. Cuticular windows on urosomites and cephalothorax not present. Body length, excluding caudal setae, from 280 to $312 \mu \mathrm{m}$, mean $304 \mu \mathrm{m}(\mathrm{n}=6)$, ornamentation of cephalothorax, somites, pigmentation and absence of nauplius eye as in male, except genital and first urosomite fused into double-somite. Cephalotorax representing about $19 \%$ of the total body length. Genital double-somite (Figs 6e, 8c) without any trace of subdivision. Genital field (Figs 6e, 8c) broader than tall, occupying anterior ventral $1 / 3$ of genital double-somite; single genital aperture covered by fused vestigial sixth legs; median copulatory pore located medially at $1 / 4$ of somite. Anal operculum convex.
\end{abstract}

CAUDAL RAMi (Figs $6 \mathrm{f}-\mathrm{g}, 8 \mathrm{~b}$ ). Shape, ornamentation and armature similar to those of male, length to width ratio: 3.5 .

Rostrum, A2 AND ORAL APPENDAGES. As in male.

A1 (Fig. 7c). Seven-segmented, aesthetasc on fourth segment longer than in male, reaching beyond end of seventh segment. First segment bare. Apical acrothek represented by two setae of different length and slender aesthetasc. Armature formula: 1-[0], 2-[1 unipinnate +4 bare], 3-[4 bare], 4-[2 bare + ae], 5-[0], $6-[0], 7-[7$ bare $+(2$ bare + ae $)]$.

P1 (Fig. 7d). Intercoxal sclerite, coxa, basis as in male but lamellar hook missing; exp and enp similar to those of male in shape, ornamentation and armature.

P2 (Fig. 7e). Intercoxal sclerite longer and narrower than in male, coxa narrower than in male, basis as in male, but with spinular row below enp insertion. Exp as in male. Enp similar in shape and ornamentation to that of male, but with two apical spinule instead of three.

P3 (Fig. 7f-g). Intercoxal sclerite small, with concave margin, bare. Coxa bare. Basis with outer seta and spinular row near seta insertion. Exp two-segmented: exp-1 as long as exp-2, with distolateral curved unipinnate spine, transversal row of spinules at $1 / 3$ and $2 / 3$ of outer margin, hyaline frill on inner distal corner; exp-2 with outer unipinnate spine and apical pinnate seta, spine length about $1 / 4$ of seta, hyaline frill on inner distal corner. Enp represented by thin and pointed segment, slightly shorter than half of corresponding exp-1, apically pinnate.

P4 (Figs 7h, 8d). Intercoxal sclerite, coxa and exp as in male. Basis bare. Enp represented by thin cylindrical segment, about $2 / 3$ length of corresponding exp-1, ending in short bipinnate seta.

P5 (Fig. 6e). Fused to intercoxal sclerite, represented by two cuticular plates shorter than in male, with same armature and without distal pore.

P6 (Fig. 6e). Vestigial, fused into simple cuticular plate, covering gonopore, unornamented and unarmed.

\title{
Variability
}

The ornamentation of male P3 exp-1 can vary, as one specimen from Vucco Ucciardo has the proximal and distal rows of respectively two and three spinules (Fig. 5e). Two males (Fig. 3b, d) and one female (Fig. 7b) from Grotta del Banco di ferro, one male (Fig. 3e) and one female (Fig. 7a) from Vucco Ucciardo carry seven setae on the caudal rami instead then 6. In one female from Vucco Ucciardo the enp P4 is fused with the apical spine (Fig. 7i). 


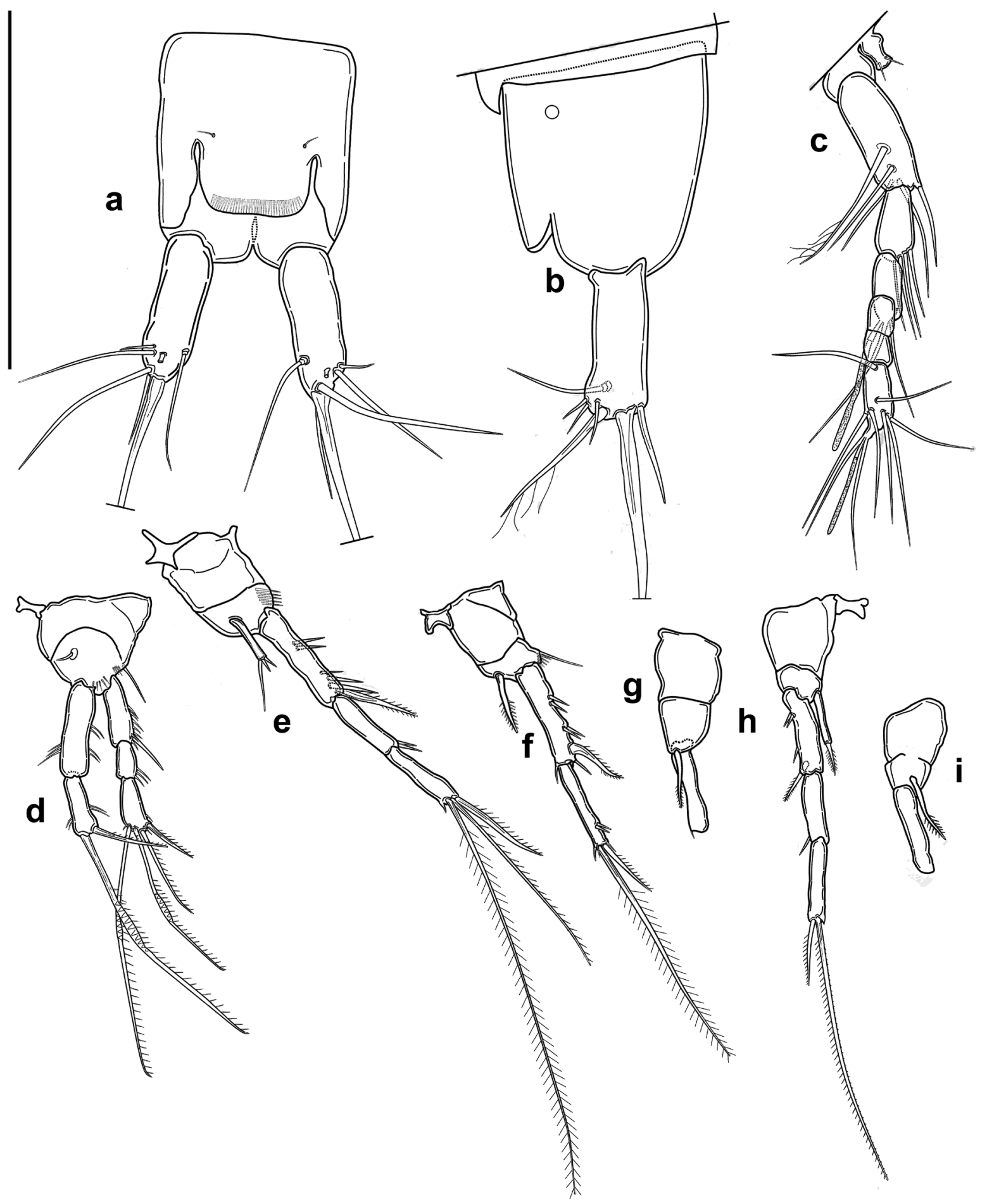

Fig. 7. Cottarellicaris sanctiangeli Bruno \& Cottarelli sp. nov., $\subsetneq$ (NHMUK). a. Anal somite, anal operculum and caudal rami, dorsal view (variability). b. Anal somite, anal operculum and caudal rami, lateral view (variability). c. Rostrum, A1. d. P1, anterior view. e. P2, inner view. f. P3, posterior view. g. Coxa, basis, enp P3, inner view. h. P4, posterior view. i. Coxa, basis, enp P4, inner view (variability). a, c-i: Grotta Grotta Vucco Ucciardo; b: Grotta del Banco di ferro. Scale bar: $50 \mu \mathrm{m}$. 

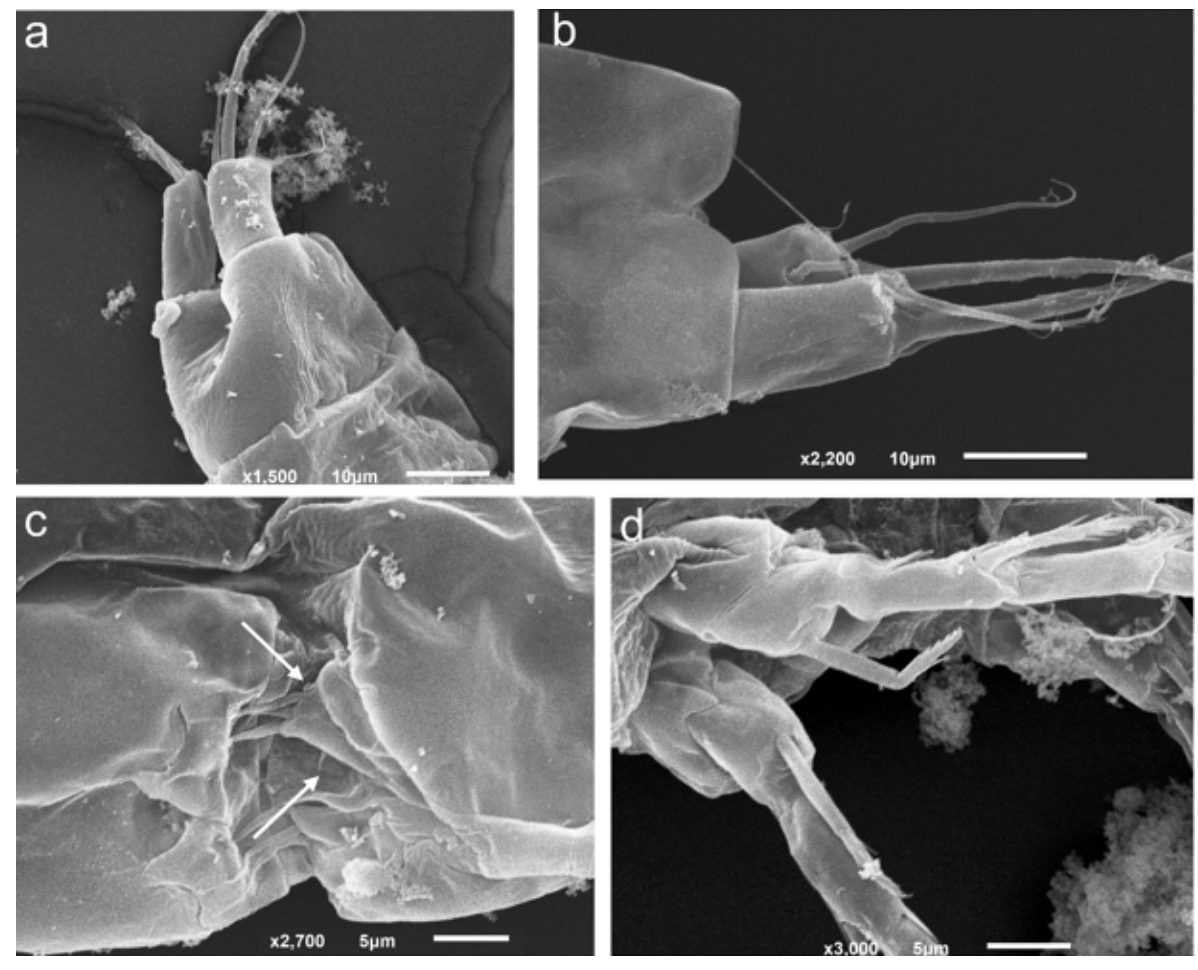

Fig. 8. Cottarellicaris sanctiangeli Bruno \& Cottarelli sp. nov. (CIME). a. $\hat{\jmath}$, anal somite, anal operculum and caudal rami, ventro-lateral view. b. + , anal somite, anal operculum and caudal rami, lateral view. c. 9, P5, P6, genital double-somite and genital field, ventral view (outermost seta, which is folded behind the P5 arrowed). d. ㅇ, enp P4. Grotta superiore di Sant'Angelo. Scale bar: $50 \mu \mathrm{m}$.

\section{Accompanying fauna}

Grotta del Banco di ferro, 10 May 2017: Maraenobiotus sp.: pool 4; Elaphoidella sp.: pool 2.

Subfamily Parastenocaridinae Chappuis, 1940

Genus Stammericaris Jakobi, 1972

Stammericaris vincentimariae Bruno \& Cottarelli sp. nov. urn:1sid:zoobank.org:act:AD8C5160-A007-4D29-974F-12925EAD0CA7

Figs 9-11, 12a; Tables 1-3

\section{Diagnosis}

Stammericaris vincentimariae Bruno \& Cottarelli sp. nov. is characterized in males primarily by the presence of one seta on the $7^{\text {th }}$ antennular segment and by the morphology of the P4: the innermost spinule of the basis inner row is inserted transversally instead of longitudinally; the enp curved plate tip is bifid instead of pointy and the distal outgrowth is flattened instead of being a seta. Females are characterized by the enp P3 much shorter than half of the first corresponding exp-1. Both sexes are characterized by caudal rami with a strong apical pointed apophysis.

\section{Etymology}

The species epithet is the genitive of the Latin first names Vincentius and Maria (Vincent and Mary in English), the names of the son and daughter of one of the authors (RG), in recognition of the great 
interest shown to speleology from their childhood onward and for participating in some of the collection campaigns.

\section{Material examined}

\section{Holotype}

ITALY • ${ }^{7}$; Cosenza Province, Cassano allo Ionio, Grotta dello Scoglio, pool 1; approximate coordinates

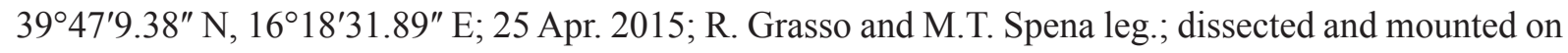
one slide labelled "Stammericaris vincentimariae holotype: male"; NHMUK 2020.33.

\section{Paratypes}

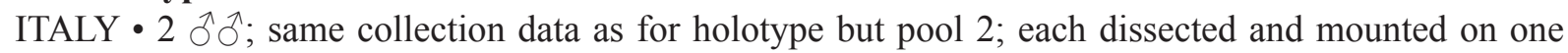
slide labelled "Stammericaris vincentimariae paratype: male"; NHMUK 2020.34 to 2020.35 • 1 त; same collection data as for preceding; dissected and mounted on one slide labelled "Stammericaris

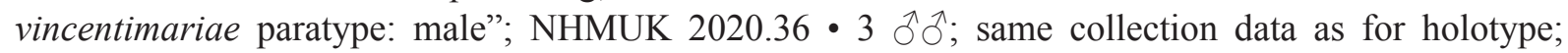
each dissected and mounted on one slide labelled "Stammericaris vincentimariae paratype: male"; NHMUK 2020.37 to 2020.39 • 1 क ; same collection data as for holotype; dissected and mounted on one slide labelled "Stammericaris vincentimariae paratype: female"; NHMUK 2020.40.

\section{Description}

\section{Adult male}

BoDy. Unpigmented, nauplius eye absent. Total body length, measured from tip of rostrum to posterior margin of caudal rami (excluding caudal setae) from 295 to $334 \mu \mathrm{m}$, mean $310 \mu \mathrm{m}(\mathrm{n}=5)$. Habitus cylindrical and slender, without any demarcation between prosome and urosome; prosome to urosome ratio: 0.80 . Free pedigerous somites without any lateral or dorsal expansions, all connected by welldeveloped arthrodial membranes. Integument weakly sclerotized, without cuticular pits, ornamented with sensilla on all somites except preanal one. Cuticular windows on urosomites (Figs 10j, 11a) and cephalothorax not visible. Cephalothorax representing about $18 \%$ of total body length. Anal somite (Fig. 9a-b) with pair of large dorsal sensilla at base of anal operculum, pair of cuticular lateral pores (one pore on each side) on proximal margin. Anal operculum (Fig. 9a-b) well developed, with straight distal margin. Anal sinus wide open. Spermatophore as in Fig. 10j.

Caudal Rami (Fig. 9a-b). Shorter than anal somite, approximately cylindrical, with strong dorsal pointed apophysis, length to width ratio: 2.7. Anterolateral accessory seta (I) and anterolateral seta (III) subequal in length, posterolateral seta (III) short, all setae inserted together distally at $3 / 4$ length of caudal ramus. Outer terminal seta (IV) long and pinnate (length seta/length caudal ramus: 1.4), inserted subterminally; inner terminal seta (V) without fracture plane. Terminal accessory seta (VI) short (length seta/length caudal ramus: 0.6 ) and smooth. Dorsal seta (VII) articulate, inserted distally at $3 / 4$ length of the caudal ramus.

Rostrum (Fig. 9d). Small, not demarcated at base, almost reaching distal margin of first antennulary segment, ornamented with two dorsal sensilla.

A1 (Fig. 9c-d). Prehensile, eight-segmented, pocket-knife type sensu Schminke (2010). First segment short; second segment longest, with seven setae, the longest seta unipinnate; third segment with four distal bare setae; fourth segment reduced to small sclerite with two short setae; fifth segment enlarged with inner round expansion with deep incision (arrowed in Fig. 9c-d) and one seta at base of distal tubercle with two long subequal setae and one large aesthetasc, reaching past end of eighth segment. Sixth segment bare, partially fused to previous one. Seventh segment with one small seta, distal anterior corner protruding as curved apophysis ending in tip. Eighth segment with seven setae and apical acrothek 


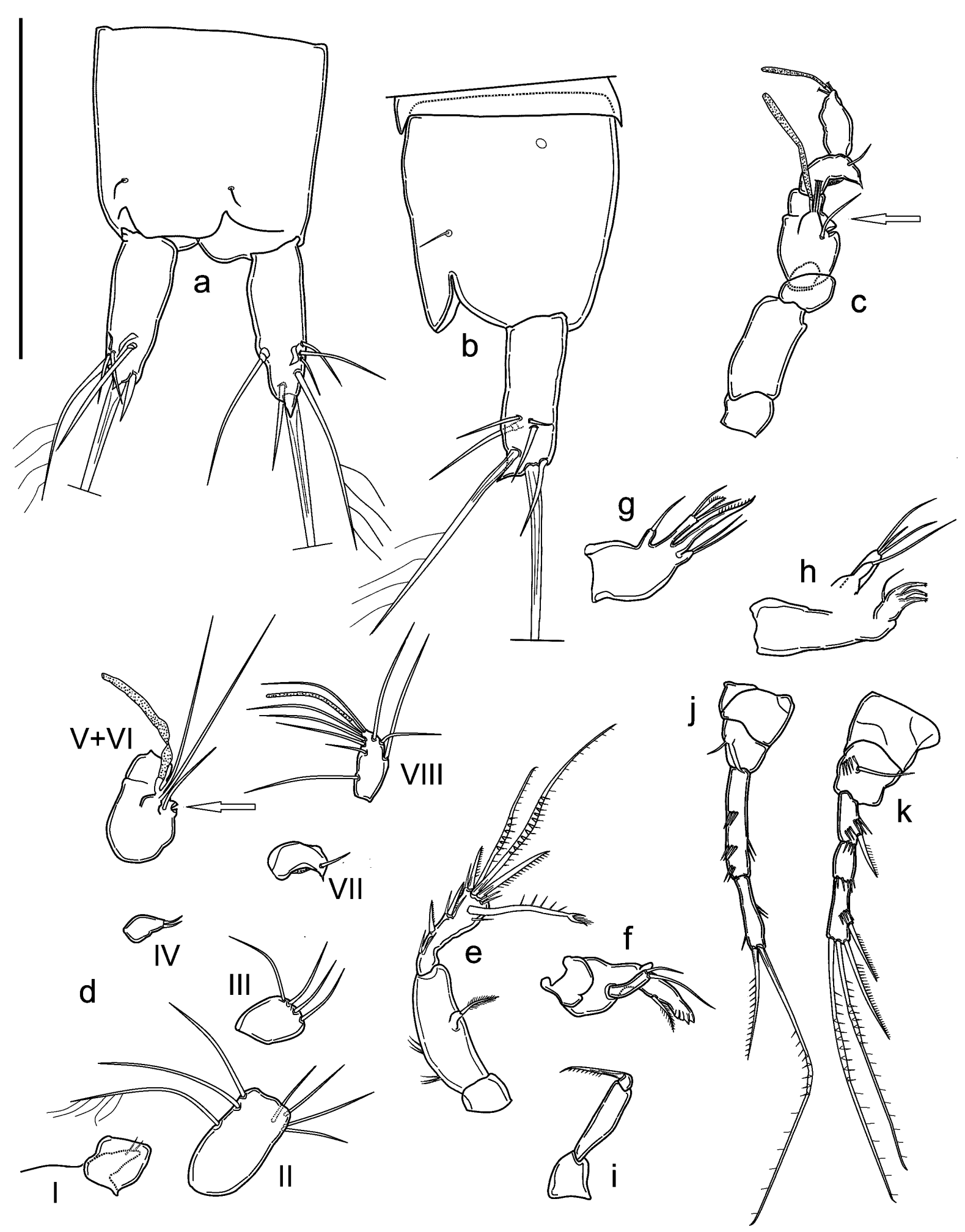

Fig. 9. Stammericaris vincentimariae Bruno \& Cottarelli sp. nov., $\widehat{\jmath}$ (NHMUK). a. Anal somite, anal operculum and caudal rami, dorsal view. b. $\hat{O}$, anal somite, anal operculum and caudal rami, lateral view. c. A1, ventral view, schematic (deep incision on fifth segment arrowed). d. Rostrum and A1, disarticulated (antennular segments marked with Roman numerals, deep incision on fifth segment arrowed). e. A2. f. Mdb. g. Mx2. h. Mx1. i. Mxp. j. P1 coxa, basis and enp, inner view. k. P1 coxa, basis and exp, outer view. Scale bar: $50 \mu \mathrm{m}$. 
represented by two setae and slender long aesthetasc. Armature formula: 1-[0], 2-[1 uniplumose +6 bare], 3-[4 bare], 4-[2 bare], 5-[3 bare + ae], 6-[0], 7-[1 bare], 8-[7 bare $+(2$ bare + ae $)$ ].

A2 (Fig. 9e). Coxa unarmed; allobasis with two transverse row of spinules on inner margin. Exp represented by small segment merged with allobasis, with bipinnate apical seta. Enp bearing two spines along inner margin, one short subdistal inner spine, one subdistal outer transformed seta, two geniculate setae and one spine apically, all spines unipinnate, all elements with long spinules near their insertions except proximalmost inner spines.

MDB (Fig. 9f). Coxal gnathobase with lateral pinnate short seta, cutting edge with apical teeth. Onesegmented palp, with two distal setae of different length.

Mx1 (Fig. 9h). Praecoxal arthrite with three apical curved robust spines apically denticled, one subdistal curved seta. Coxal endite long, with one apical seta. Basis cylindrical, with three distal bare setae. Enp and exp absent (fused to basis without trace).

Mx2 (Fig. 9g). Basis with two endites, proximal endite short, with one thin, bare seta; distal endite cylindrical, longer, armed apically with two subequal thin bare setae and one transformed, leaf-like pinnate seta; proximal endopodal segment drawn into apical unipinnate claw; distal endopodal segment with two long setae of equal length.

Mxp (Fig. 9i). Subchelate, composed of small and unarmed syncoxa, basis slim and elongate, unarmed, 1 -segmented enp fused to claw-like apical seta.

P1 (Fig. 9j-k). With smooth and small intercoxal sclerite; coxa bare. Basis large, armed with single slender seta on outer margin, and small seta and lamellar hook on inner margin of basis near enp insertion. Exp three-segmented, slightly shorter than enp; exp-1 with thin unipinnate spine on outer distal corner; exp-2 shortest and unarmed; exp-3 with two geniculate and one normal unipinnate apical setae, and one subapical unipinnate spine. Enp two-segmented; enp-1 longer than first two segments of corresponding exp, with one transversal row of spinules on outer margin, and three on inner margin. Enp-2 thinner and shorter than enp-1, with two spinules at $2 / 3$ of inner margin; long, geniculate unipinnate seta, and shorter unipinnate seta on apex.

P2 (Fig. 10a). With smooth and small intercoxal sclerite, three times as wide as long, with slightly concave distal margin. Coxa bare. Basis unarmed, with row of four spinules on outer margin. Exp three-segmented, exp-1 longest, with three transversal rows of spinules and transversal row of spinules proximal to strong distolateral bipinnate spine. Second and third segments of same length, exp-2 unarmed, with distal row of spinules; exp-3 armed with subapical outer unipinnate spine, apical bipinnate seta and unipinnate spine, ornamented with outer subapical spinules, distal row of spinules, and inner hyaline frill. Enp one-segmented, slightly longer than half length of corresponding exp-1, but reaching approximately to half length of exp-1, cylindrical, with subapical seta about as long as segment and three short apical spinules.

P3 (Fig. 10b-c). Intercoxal sclerite narrow and tall, trapezoidal, unornamented, with slightly concave distal margin. Coxa with two outer spinular rows. Basis robust, with long, slender, smooth outer seta and transverse spinule row above. Enp reduced to short seta. Exp-1 outer margin with one proximal group of two spinules, distal group of two large and two smaller spinules (almost divided into two groups). Exp-2 fused with exp-1, without ornamentation, prolonged into long apophysis slightly bent inwards, with pointed tip surrounded by hyaline membrane (arrowed in Fig. 10b). Distal thumb represented by thin and pointed segment, shorter than apophysis. 


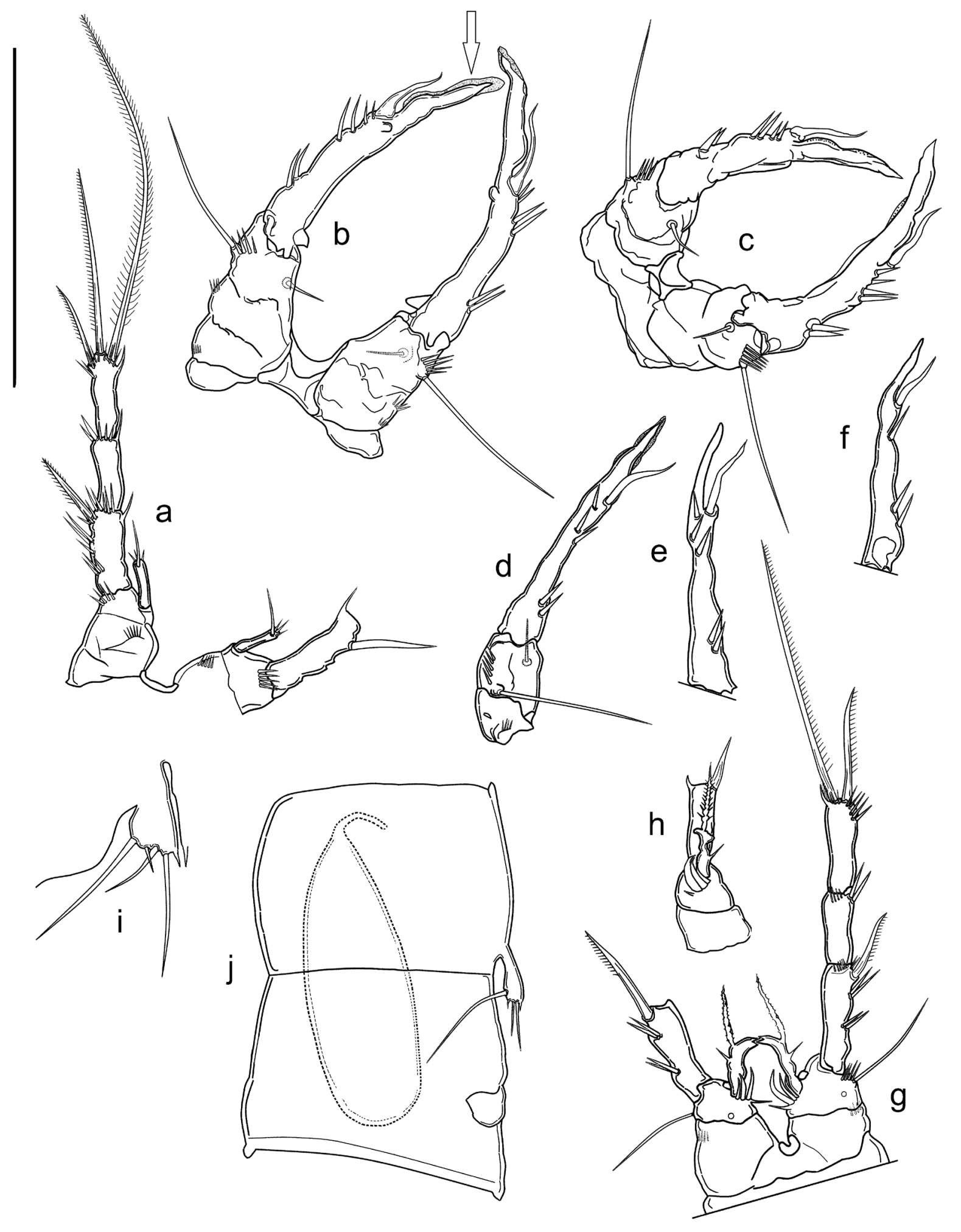

Fig. 10. Stammericaris vincentimariae Bruno \& Cottarelli sp. nov., § (NHMUK). a. P2, anterior view. b. P3, posterior view (hyaline membrane on tip of apophysis arowed). c. P3, anterior view. d. P3, outer view (variability). e. P3 exp, outer view (variability). f. P3 exp, outer view (variability). g. P4. h. P4 enp. i. P5. j. P5, P6, first and second urosomites, spermatophore, lateral view. Scale bar: $50 \mu \mathrm{m}$. 
P4 (Fig. 10g-h). Intercoxal sclerite smaller than in P1 or P2, with concave, smooth distal margin. Coxa with spinular row on outer margin. Basis armed with single slender seta on outer margin; ornamented with row of spinules at base of outer seta and pore. Row of three spinules of increasing size, slightly curved inwards aligned along inner margin, smaller one close to enp; one spiniform process on inner margin projecting inwards. Exp three-segmented, slender, all segments approximately of the same length; exp-1 with distolateral unipinnate spine; with transversal row of two spinules at $1 / 3$ of outer margin and below distolateral spine insertion, spinular row along distal margin; exp-2 unarmed, with spinular row along distal margin and two spinules at outer distal corner; exp-3 armed with outer unipinnate spine and long apical unipinnate seta, spine length less than $1 / 2$ of seta length; ornamentation represented by row of apical spinules, row of spinules along distal outer margine, inner hyaline frill. Enp one-segmented and as long as first two segments of corresponding exp, represented by curved plate with bifid tip, carrying at outer border two outgrowths, distal one being long denticled lamella and proximal one plain small spiniform outgrowth.

P5 (Figs 10i-j, 11a). Fused to intercoxal sclerite; represented by two trapezoidal cuticular plates with long basipodal seta. Armature on free distal margin, from inner to outer: one spiniform process, three bare setae, outermost very short, remaining two subequal.

P6 (Figs 10j, 11a). Vestigial, fused into simple cuticular plate, unornamented and unarmed.

\section{Adult female}

Habitus. Cylindrical and slender, without any demarcation between prosome and urosome. Free pedigerous somites without any lateral or dorsal expansions, all connected by well-developed arthrodial membranes. Integument weakly sclerotized, without cuticular pits, ornamented with sensilla on all somites except preanal one. Cuticular windows on urosomites and cephalothorax not visible. Body length, excluding caudal setae, from 290 to $340 \mu \mathrm{m}$, mean $314 \mu \mathrm{m}(\mathrm{n}=5)$, ornamentation of cephalothorax, somites, pigmentation and absence of nauplius eye as in male, except genital and first urosomite fused into double-somite. Cephalotorax representing about $19 \%$ of total body length. Prosome/urosome ratio: 0.80. Genital double-somite (Fig. 12a) without any trace of subdivision. Genital field (Fig. 12a) broader than tall, occupying anterior ventral $1 / 3$ of genital double-somite, with pair of ventrodistal pores; single genital aperture covered by fused vestigial sixth legs; median copulatory pore located medially at $1 / 3$ of double-somite length. Anal operculum and anal sinus (Fig. 11b) as in male.

Caudal Rami (Fig. 11b). Shape, ornamentation and armature similar to those of male, length/width ratio: 3.3 .

Rostrum, A2 AND ORAL APPENDAGES. As in male.

A1 (Fig. 11c). Seven-segmented, aesthetasc on fourth segment shorter than in male, reaching below end of seventh segment. First segment bare. Second segment longest. Apical acrothek represented by two setae of subequal length and slender aesthetasc. Armature formula: 1-[0], 2-[1 pinnate +3 bare], 3-[4 bare], 4-[2 bare + ae], 5-[0], 6-[0], 7-[7 bare + $(2$ bare + ae $)]$.

P1 (Fig. 11d). Intercoxal sclerite, coxa, basis ornamentation as in male, but with inner spiniform seta (lamellar hook missing), outer seta missing; exp and enp similar to those of male in shape, ornamentation and armature.

P2 (Fig. 11e). Intercoxal sclerite, coxa, basis and exp as in male. Enp similar in shape and ornamentation to that of male, but subapical seta shorter.

P3 (Fig. 11f). Intercoxal sclerite small, trapezoidal, with concave margin, bare. Coxa with outer spinular row. Basis with outer spinular row; exp two-segmented: exp-1 slightly longer than exp-2, with distolateral 


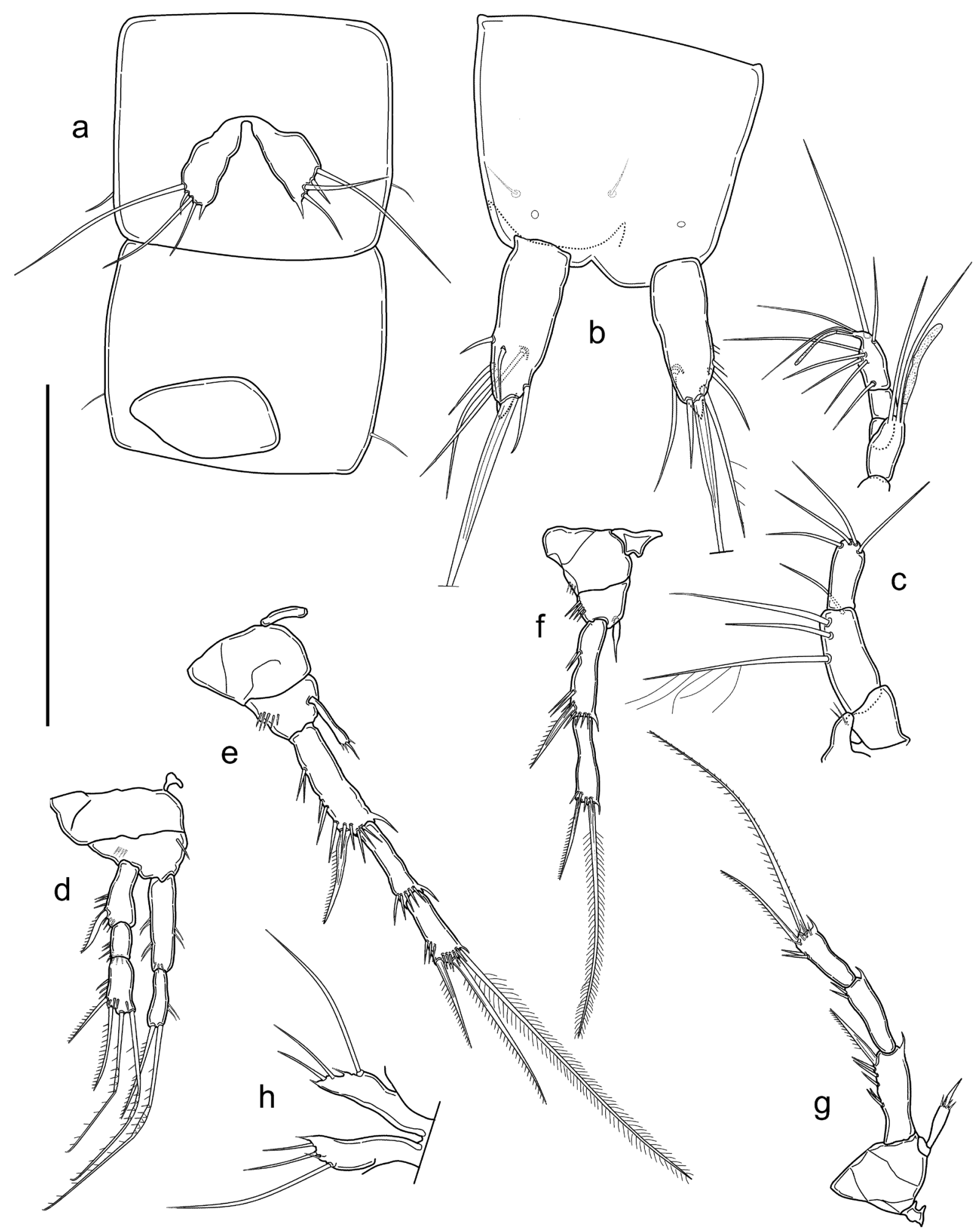

Fig. 11. Stammericaris vincentimariae Bruno \& Cottarelli sp. nov. (NHMUK). a. §ै, P5, P6, first and second urosomites, ventral view. b. + , anal somite, anal operculum and caudal rami, ventral view. c. + , rostrum and $\mathrm{A} 1$. d. + , $\mathrm{P} 1$, posterior view. e.,$+ \mathrm{P} 2$, anterior view. f. + , $\mathrm{P} 3$, anterior view. g. $q, \mathrm{P} 4$, anterior view. h. ㅇ, P5. Scale bar: $50 \mu \mathrm{m}$. 

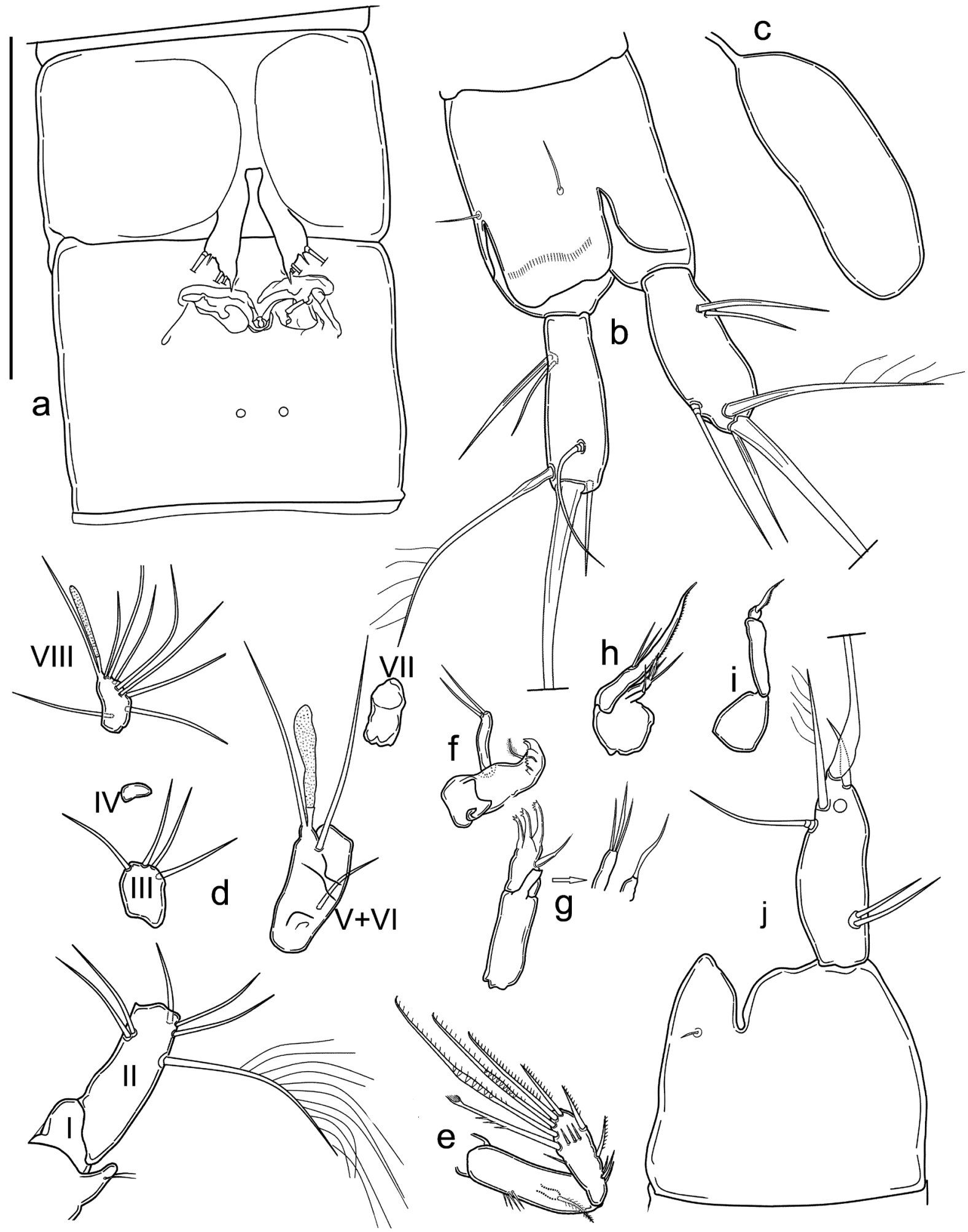

Fig. 12. a. Stammericaris vincentimariae Bruno \& Cottarelli sp. nov., $q$ (NHMUK), first urosomite, P5, P6, genital double-somite and genital field, ventral view. - b-j. Proserpinicaris specincola

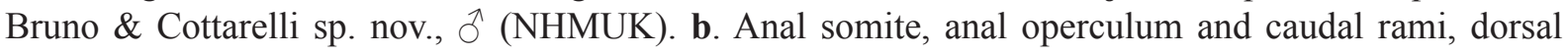
view. c. Spermatophore. d. Rostrum and A1, disarticulated (antennular segments marked with roman numerals). e. A2. f. Mdb. g. Mx1. h. Mx2. i. Mxp. j. Anal somite, anal operculum and caudal rami, lateral view. Scale bar: $50 \mu \mathrm{m}$. 
curved unipinnate spine, transversal row of spinules at $1 / 3$ and $2 / 3$ of outer margin, distal spinular row, hyaline frill on inner distal corner; exp-2 with subapical outer unipinnate spine and apical bipinnate seta, spine length about $1 / 3$ of seta, with distal spinular row and hyaline frill on inner distal corner. Enp represented by thin and pointed segment, much shorter than half of corresponding exp-1.

P4 (Fig. 11g). Intercoxal sclerite, coxa and exp as in male. Basis bare. Enp represented by thin cylindrical segment, slightly shorter than $1 / 2$ the length of corresponding exp-1, ending in spiniform seta with spinules around the insertion.

P5 (Figs 11h, 12a). Fused to intercoxal sclerite, represented by cuticular plate more elongated than in male, with inner spiniform process shorter than in male, outer short setae transformed in spiniform process, remaining ornamentation represented by two setae, innermost shortest and long basipodal seta.

P6 (Fig. 12a). Vestigial, fused into simple cuticular plate, covering gonopore, unornamented and unarmed.

\section{Variability}

One male specimen with a distal row of three spinules on the outer margin of P3-Exp-1 (Fig. 10d). A second specimen with three spinules on one P3 (Fig. 10e) and one spinule on the other P3 (Fig. 10f).

Subfamiliy Fontinalicaridinae Schminke, 2010

Genus Proserpinicaris Jakobi, 1972

Proserpinicaris specincola Bruno \& Cottarelli sp. nov. urn:1sid:zoobank.org:act:7368747C-5CFB-4AF0-86E2-69860DF7E985

Figs 12b-j, 13-14; Table 1

\section{Diagnosis}

Proserpinicaris specincola Bruno \& Cottarelli sp. nov. is characterized by the morphology of P3 in the males: the inner margin of exp-1 is straight, without a beak and/or one or more chitinous lobes; exp-2 is prolonged into a finger-like apophysis. The basis $\mathrm{P} 4$ of males has a long and pointed process, as long as exp-1, inserted between enp and exp. Both sexes are characterized by the reduced size, a thin cuticle and the lack of integumental windows on the urosomites and the cephalothorax, and the apical seta on $\mathrm{P} 2$ enp are missing.

\section{Etymology}

The species epithet is the genitive singular of the Latin word 'specus', meaning 'cave' and the nominative 'incola', meaning 'inhabitant', underlining that this species is a cave-dweller.

\section{Material examined}

\section{Holotype}

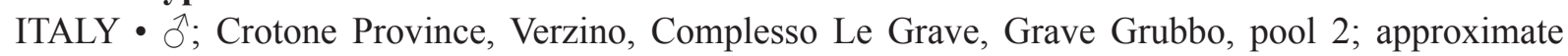
coordinates $39^{\circ} 15^{\prime} 41.4^{\prime \prime}$ N, 1651'45.1" E; 28 Aug. 2015; R. Grasso and M.T. Spena leg.; dissected and mounted on one slide labelled "Proserpinicaris specincola holotype: male"; NHMUK 2020.41.

\section{Paratypes}

ITALY • 1 万े; same collection data as for holotype, pool 3; 21 Apr. 2018; dissected and mounted on one slide labelled "Proserpinicaris specincola paratype: male"; NHMUK 2020.42 • 1 q, same collection data as for holotype; mounted on one slide labelled "Proserpinicaris specincola paratype: female"; 
NHMUK 2020.43 • 1 क , same collection data as for holotype; dissected and mounted on one slide labelled "Proserpinicaris specincola paratype: female"; NHMUK 2020.44.

\section{Description}

\section{Adult male}

BoDy. Unpigmented, nauplius eye absent. Total body length, measured from tip of rostrum to posterior margin of caudal rami (excluding caudal setae) from 372 to $384 \mu$ m, mean $363 \mu \mathrm{m}(\mathrm{n}=2)$. Habitus cylindrical and slender, without any demarcation between prosome and urosome; prosome to urosome ratio: 0.90 . Free pedigerous somites without any lateral or dorsal expansions, all connected by welldeveloped arthrodial membranes. Integument weakly sclerotized, without cuticular pits, ornamented with sensilla on all somites except preanal one. Cuticular windows on urosomites and cephalothorax not observed. Cephalothorax representing about $15 \%$ of total body length. Anal somite (Fig. 12b, j) with pair of large dorsal sensilla at base of anal operculum. Anal operculum (Fig. 12b, j) well developed, with straight distal margin. Anal sinus wide open. Spermatophore as in Fig. 12c.

Caudal Rami (Fig. 12b, j). Shorter than anal somite, approximately cylindrical, length to width ratio: 3. Anterolateral accessory seta (I) and anterolateral seta (III) long and subequal in length, smooth; posterolateral seta missing, all setae inserted together proximally at $1 / 3$ length of caudal ramus. Outer terminal seta (IV) long and unipinnate (length seta/length caudal ramus: 1.3), inserted subterminally; inner terminal seta (V) without fracture plane. Terminal accessory seta (VI) short (length seta/length caudal ramus: 0.9 ) and smooth. Dorsal seta (VII) articulate, inserted distally at $3 / 4$ length of caudal ramus.

Rostrum (Fig. 12d). Small, not demarcated at base, almost reaching distal margin of A1, ornamented with two dorsal sensilla.

A1 (Fig. 12d). Prehensile, eight-segmented coiled type sensu Schminke (2010). First segment short, second segment longest, with six setae, longest seta unipinnate. Third segment with four distal bare setae; fourth segment reduced to small bare sclerite. Fifth segment enlarged, with lateral seta and distal tubercle with two long subequal setae and one short aesthetasc. Sixth segment bare, partially fused to previous one. Seventh segment bare. Eighth segment with seven setae and apical acrothek represented by two seta and short aesthetasc. Armature formula: 1-[0], 2-[1 uniplumose +5 bare], 3-[4 bare], 4-[0], 5-[3 bare + ae], 6-[0], 7-[0], 8-[7 bare $+(2+$ ae $)]$.

A2 (Fig. 12e). Coxa unarmed; allobasis with one transverse row of four spinules on inner margin. Exp represented by small segment merged with allobasis, with pinnate apical seta. Enp bearing three proximal spinules and two unipinnate spines along inner margin, one transformed seta subapically on outer margin; one spine, two geniculate and one normal setae, all unipinnate, on the distal margin.

MDв (Fig. 12f). Coxal gnathobase with lateral pinnate short seta, cutting edge with apical teeth. Onesegmented palp, with two distal setae of subequal length.

Mx1 (Fig. 12g). Praecoxal arthrite with three apical curved robust spines apically denticled, one subdistal curved seta. Coxal endite long, with one apical seta. Basis cylindrical, with three distal bare setae. Enp and exp absent (fused to basis without trace).

Mx2 (Fig. 12h). Basis with two endites, proximal endite short, with one thin, bare seta; distal endite cylindrical, longer, with two bare and one leaf-like seta; proximal endopodal segment drawn into apical unipinnate claw; distal endopodal segment small, with two long setae of equal length.

Mxp (Fig. 12i). Subchelate, composed of small and unarmed syncoxa, basis slim and elongate, unarmed, 1 -segmented enp fused to the claw-like apical seta. 
BRUNO M.C. et al., New Parastenocarididae (Copepoda, Harpacticoida) from Southern Italy

P1 (Fig. 13a). With smooth and small intercoxal sclerite; coxa large and bare. Basis large, armed with single slender seta on outer margin. Exp three-segmented, slightly longer than enp, exp-1 with thin spiniform seta on outer distal corner; exp-2 shortest and unarmed; exp-3 with two geniculate and one normal apical unipinnate setae and one unipinnate subapical seta. Enp two-segmented; enp-1 as long as first two segments of the corresponding exp, with two transversal rows of spinules on outer margin, longitudinal row of spinules at $2 / 3$ of inner margin. Enp-2 thinner and shorter than enp-1, with three spinules at $2 / 3$ of inner margin and four at $2 / 3$ of outer margin; with long, geniculate seta and shorter unipinnate seta on apex.

P2 (Fig. 13b). With smooth and small intercoxal sclerite, three times as wide as long; coxa bare. Basis unarmed, with row of four spinules on outer margin; one proximal transversal row of spinules and another transversal row between enp and exp. Exp three-segmented, exp-1 longest, with two transversal rows of spinules, transversal row of spinules proximal to strong distolateral bipinnate spine, hyaline frill on inner distal corner. Second and third segments of same length; exp-2 unarmed, with row of spinules on distolateral corner, hyaline frill on distal inner corner; exp-3 armed with subapical outer unipinnate spine, apical bipinnate seta and unipinnate spine, and inner hyaline frill. Enp one-segmented, about half length of corresponding exp-1, cylindrical, with small outer spinule inserted at half-length and two short apical spinules.

P3 (Fig. 13c). Intercoxal sclerite narrow and tall, trapezoidal, unornamented, with slightly concave distal margin. Coxa bare. Basis robust, with long, slender, smooth outer seta, one transverse spinule row above and one row of small, elongate lamellae inserted subdistally and transversally on ventral surface. Enp reduced to short, bare seta. Exp-1 rectangular, outer margin without ornamentation, inner margin straight, without buldges; exp-2 fused with exp-1, without ornamentation, prolonged into short fingerlike apophysis with round tip and apical short spine. Distal thumb represented by leaf-like segment, longer than apophysis.

P4 (Fig. 13d). Intercoxal sclerite smaller than in P1 or P2, with concave, smooth distal margin; coxa bare. Basis armed with single slender seta on outer margin; ornamented with row of spinules on outer margin; with long and pointed process, as long as exp-1, inserted between enp and exp. Exp threesegmented, slender, all segments approximately of same length but progressively thinner; exp-1 slightly curved inwards, with distolateral bipinnate spine; proximal group of three spinule and distal group of two spinules on outer margin, longitudinal row of four long setules distally along inner margin and distal spinular row; exp-2 unarmed, with distal spinular row; exp-3 armed with apical unipinnate spine and long apical unipinnate seta, spine length less than $1 / 3$ of seta length, ornamented with distal spinular row and inner hyaline frill. Enp one-segmented, as long as first segment of corresponding exp, spiniform, pointing inwards and crenulated in proximal half, smooth in distal half, ending in tip.

P5 (Fig. 13e). Fused to intercoxal sclerite; represented by triangular cuticular plate, inner distal corner produced into very large spiniform process, ornamented with short row of three spinules along inner margin and cuticular pore on anterior surface, armed with long basipodal seta and two bare setae of subequal length.

P6 (Fig. 13e). Vestigial, fused into simple cuticular plate, unornamented and unarmed.

\section{Adult female}

Habitus. Cylindrical and slender, without any demarcation between prosome and urosome. Free pedigerous somites without any lateral or dorsal expansions, all connected by well-developed arthrodial membranes. Integument weakly sclerotized, without cuticular pits, ornamented with sensilla on all somites except preanal one. Cuticular windows on urosomites and cephalothorax not present. Body length, excluding caudal setae, from 355 to $376 \mu \mathrm{m}$, mean $363 \mu \mathrm{m}(\mathrm{n}=2)$, ornamentation of cephalothorax, 


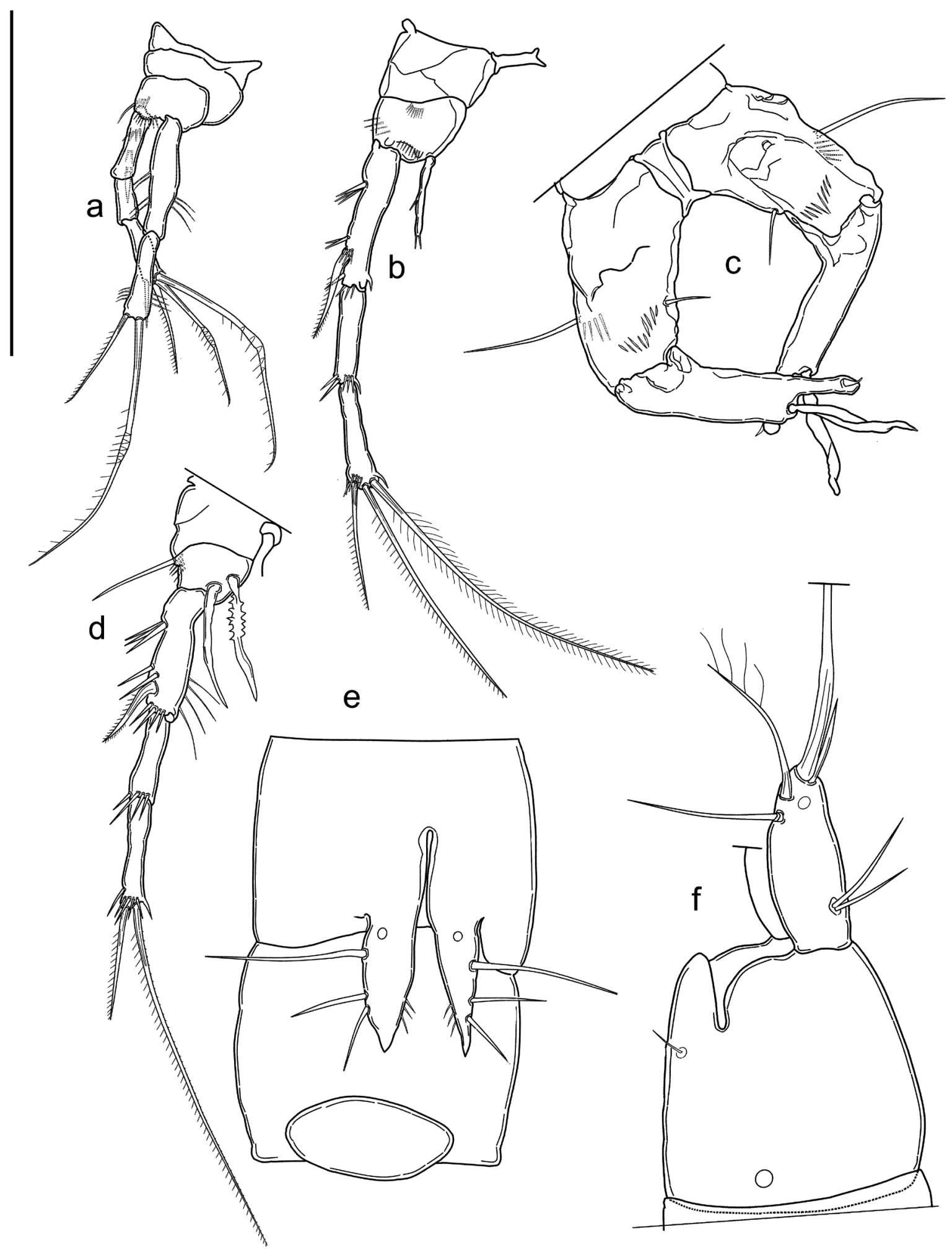

Fig. 13. Proserpinicaris specincola Bruno \& Cottarelli sp. nov. (NHMUK). a. $\widehat{\partial}, \mathrm{P} 1$, posterior view.

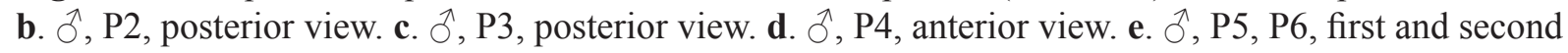
urosomites, ventral view. f. + , anal somite, anal operculum and caudal rami, lateral view. Scale bar: 50 micrometers. 
somites, pigmentation, and absence of nauplius eye as in male, except genital and first urosomite fused into double-somite. Cephalotorax representing about $16 \%$ of total body length. Prosome/urosome ratio: 0.90. Genital double-somite (Fig. 14j) without any trace of subdivision, with pair of ventral cuticular pores. Genital field as in Fig. 14j. Anal somite with pair of lateral basal pores (Fig. 13f). Anal operculum and anal sinus as in male.

CAUdAl RAmi (Fig. 13f). Shape, ornamentation and armature similar to those of male, length to width ratio: 2.6
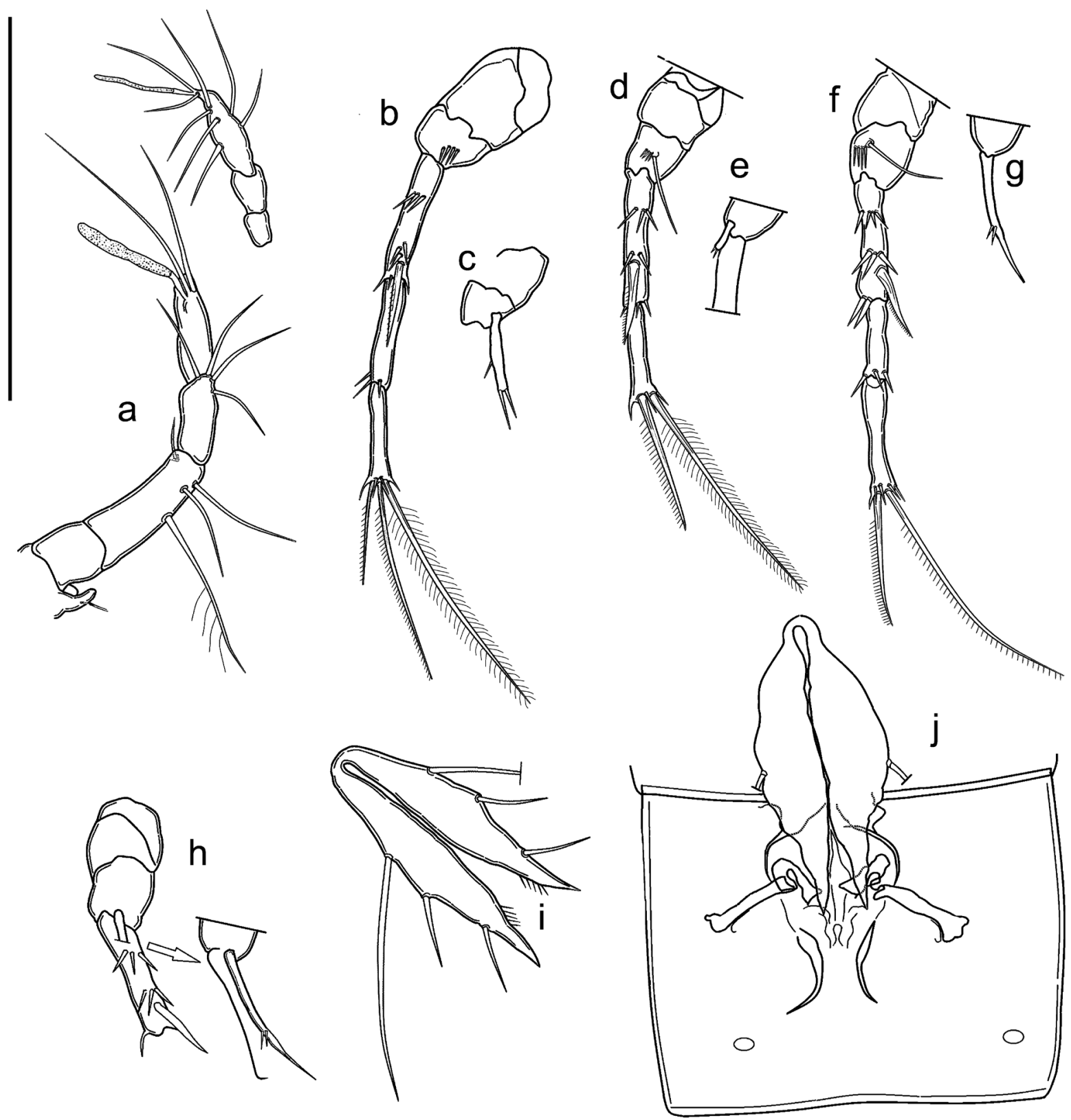

Fig. 14. Proserpinicaris specincola Bruno \& Cottarelli sp. nov., $q$ (NHMUK). a. Rostrum and A1. b. P2 coxa, basis and exp, outer view. c. P2, enp. d. P3, basis and exp, outer view. e. P3, enp. f. P4, basis and exp, outer view. g. P4, enp. h. P4 coxa, basis and first exopodal segment, and enp, inner view. i. P5. j. P5, P6, genital double-somite and genital field, ventral view. Scale bar: $50 \mu \mathrm{m}$. 
Rostrum, A2, ORAL APPENDAGES AND P1. As in male.

A1 (Fig. 14a). Seven-segmented, aesthetasc on fourth segment shorter than in male, reaching below end of seventh segment. First segment bare, second segment longest. Apical acrothek represented by two setae of subequal length and slender aesthetasc. Armature formula: 1-[0], 2-[1 unipinnate +3 bare], 3-[4 bare], 4-[2 bare + ae], 5-[0], 6-[0], 7-[7 bare + $(2$ bare + ae $)]$.

P2 (Fig. 14b-c). Basis and exp as in male. Enp similar in shape and ornamentation to that of the male, but apical spinules longer.

P3 (Fig. 14d-e). Intercoxal sclerite small, with concave margin, bare. Coxa bare. Basis with outer seta and spinular row near seta insertion. Exp two-segmented: exp-1 longer than exp-2, with subdistal unipinnate spine and transversal row of three and two spinules at $1 / 3$ and $2 / 3$ of outer margin, hyaline frill on inner distal corner; exp-2 with apical outer unipinnate spine and apical bipinnate seta, spine length about $1 / 2$ of seta, hyaline frill on inner distal corner. Enp represented by thin cylindrical segment, slightly shorter than $1 / 3$ of exp-1, with apical row of short spinules.

P4 (Fig. 14f-h). Intercoxal sclerite, coxa and exp as in male. Basis without long spinule between insertion of exp and enp. Enp represented by pointed cylindrical segment, slightly longer than exp-1, with two spinules inserted at $2 / 3$ of margin.

P5 (Fig. 14i-j). Fused to intercoxal sclerite, represented by cuticular plate, more elongated than in male, without basal pore and with five spinules inserted at about $4 / 5$ on inner margin; armed with long basipodal seta and two bare setae of subequal length.

P6 (Fig. 14j). Vestigial, fused into simple cuticular plate, covering gonopore, unornamented and unarmed.

\section{Accompanying fauna}

Grave Grubbo, 28 Aug. 2015: Nitocrella stammeri Chappuis, 1938: pool 3, pool 8, pool 11; Speocyclops sp.: pool 6, pool 8; Bryocamptus sp.: pool 6; Attheyella crassa (G.O. Sars, 1863): pool 9.

\section{Molecular phylogenetic analysis}

Overall, 38 harpacticoids specimens, 34 of which belonging to the family Parastenocarididae, were analysed and included in the analyses (Table 2). After trimming out the tails of the sequences, which were not present in all the individuals, we obtained a properly aligned $2090 \mathrm{bp}$-long combined fragment. The COI and $18 \mathrm{~S}$ sequences produced in the frame of present work were deposited in GenBank (Table 2). The BI and ML trees based on the combined dataset and rooted on Bryocamptus stillae show a congruent topology, in agreement with the current morphology-based taxonomy, with a wellsupported parastenocaridiid clade (Fig. 15). Within the analysed Parastenocarididae, a first dichotomy separates Proserpinicaris amalasuntae from a clade including, with a sister-taxa relationship, the Parastenocaridinae Cottarellicaris sanctiangeli Bruno \& Cottarelli sp. nov. and Stammericaris spp. Interestingly, specimens of Cottarellicaris sanctiangeli sp. nov. from Vucco Ucciardo and Grotta superiore di Sant'Angelo shared a unique haplotype, whereas a different haplotype occured in specimens

Fig. 15 (opposite page). Bayesian phylogram ( $95 \%$ majority rule consensus tree) of the investigated Parastenocarididae Chappuis, 1940 based on the 2090 bp fragment of the combined dataset including COI and 18S sequences. Bryocamptus (Rheocamptus) stillae Cottarelli \& Bruno, 2012 and Bereraia sp. used as outgroups to root the tree. Node statistical support is reported as nodal posterior probabilities (Bayesian Inference of phylogeny, BI) / bootstrap values (Maximum Likelihood, ML). Asterisks indicate a bootstrap support value lower than 50 . 


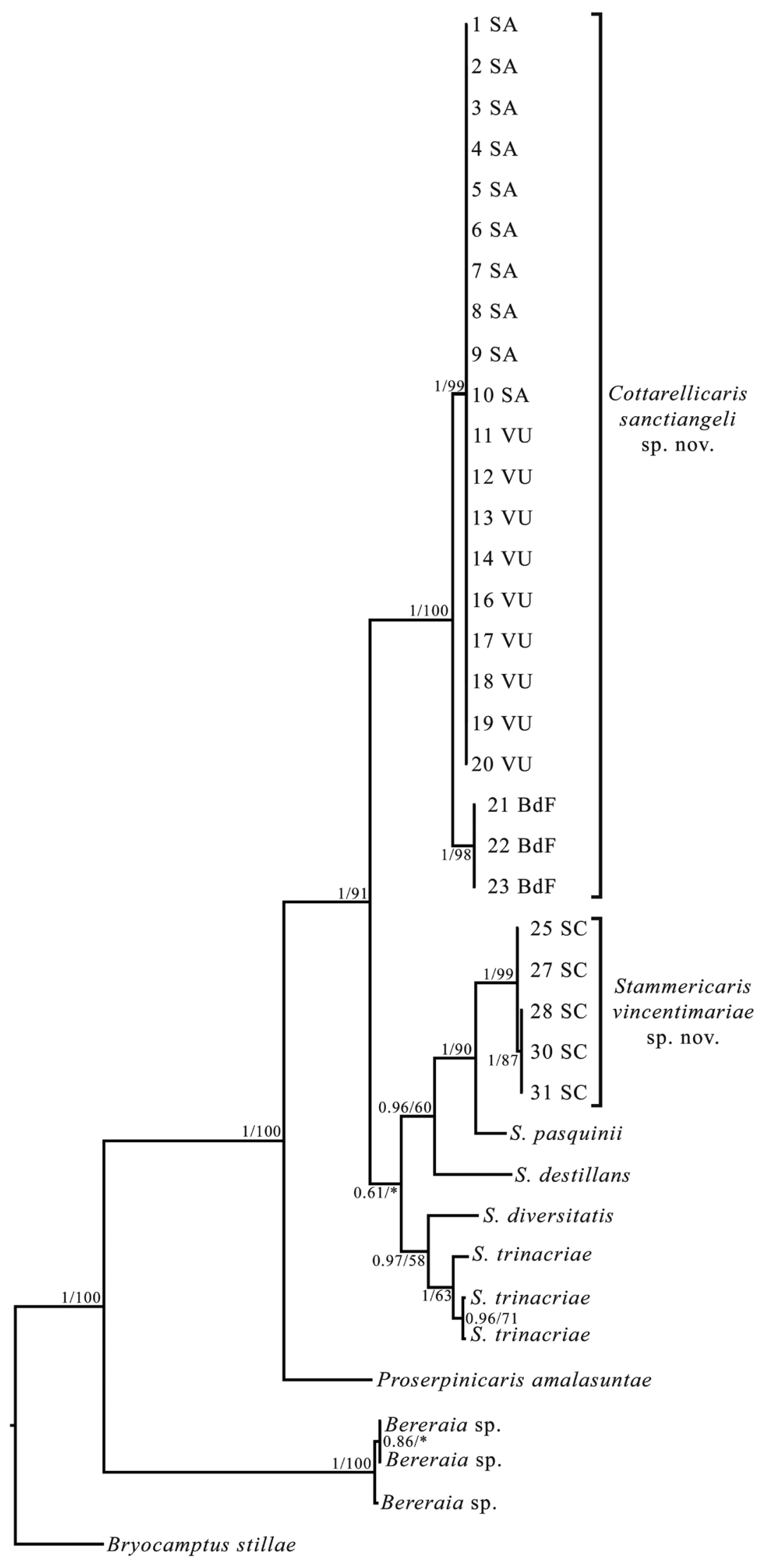

0.02 
Table 3. Pairwise distances ( $p$-distance model) among COI sequences between the analysed species of Parastenocarididae.

\begin{tabular}{lccccccc}
\hline Species & $\mathbf{1}$ & $\mathbf{2}$ & $\mathbf{3}$ & $\mathbf{4}$ & $\mathbf{5}$ & $\mathbf{6}$ & $\mathbf{7}$ \\
\hline 1. Stammericaris vincentimariae & - & & & & & & \\
2. Stammericaris pasquinii & 0.129 & - & & & & & \\
3. Stammericaris destillans & 0.196 & 0.223 & - & & & & \\
4. Stammericaris diversitatis & 0.249 & 0.262 & 0.235 & - & & & \\
5. Stammericaris trinacriae & 0.226 & 0.206 & 0.209 & 0.145 & - & & \\
6. Cottarellicaris sanctiangeli & 0.259 & 0.227 & 0.250 & 0.224 & 0.228 & - & \\
7. Proserpinicaris amalasuntae & 0.320 & 0.274 & 0.271 & 0.281 & 0.264 & 0.306 & - \\
\hline
\end{tabular}

of $C$. sanctiangeli sp. nov. collected in Grotta del Banco di ferro. Conversely, two haplotypes were observed in specimens of Stammericaris vincentimariae Bruno \& Cottarelli sp. nov. from Grotta dello Scoglio, constituting a well-supported clade with sister-clade relationship with S. pasquinii (Fig. 15).

Based on the COI dataset, pairwise distances (Table 3) between S. vincentimariae Bruno \& Cottarelli sp. nov. and the other species of Stammericaris ranged between $12.9 \%$ (S. pasquinii) and 24.9\% (S. diversitatis); the distances between Cottarellicaris sanctiangeli Bruno \& Cottarelli sp. nov. and all the species of Stammericaris ranged between 22.4\% (S. diversitatis) and 25.9\% (S. vincentimariae sp. nov.). Species belonging to different subfamilies were most distant (i.e., $32 \%$ pairwise distance for P. amalasuntae vs $S$. pasquinii).

\section{Discussion}

\section{Taxonomic definition and affinities of the three new species}

To properly discuss the taxonomy and affinities of the three new species described herein, we examined the drawings and descriptions available in literature, and the specimens of the 27 following taxa from our collection: Cottarellicaris aphroditis, C. etrusca, C. hera, C. luciae, C. oligoalina, C. rivi, C. sibaritica, C. stellae, Cottarellicaris sp. (Asinara Island, Sardinia, unpublished), Cottarellicaris sp. (Montecristo Island, Sardinia, unpublished), Cottarellicaris sp. (Belice River mouth, Sicily, unpublished), Proserpinicaris proserpina, P. admete, P. amalasuntae, P. ima, P. kalypso, Proserpinicaris sp. (Asinara Island, Sardinia, Italy), Proserpinicaris sp. (Turkey, hyporheic, Central Anatolia, unpublished), Stammericaris amyclaea, S. destillans, S. diversitatis, S. lorenzae, S. orcina, S. pasquinii, S. trinacriae, Stammericaris sp. (Trento, Northern Italy, unpublished), Stammericaris sp. (Egridir Lake, Turkey, unpublished).

Schminke (2013) erected the genus Cottarellicaris based on the following morphological characters:

i) male A1 eight-segmented and of the "pocket-knife" type;

ii) P1 basis in male with or without hook and seta near the endopod insertion;

iii) $\mathrm{P} 3$ enp in female as long as, or longer than exp-1;

iv) outer margin of $\mathrm{P} 3$ exp-1 in male proximally with one or no spinule, distally with 1-4 spinules, apophysis leaf-like with an acute tip, as long as thumb or shorter;

v) P4 basis in male with an inner row of 1-4 curved spinules decreasing in size laterally, P4 endopod in male a curved plate with a pointed inner tip carrying two outgrowths at its outer border, the distal one being an elongate lamella with undulating (crenulate) margins; 
BRUNO M.C. et al., New Parastenocarididae (Copepoda, Harpacticoida) from Southern Italy

vi) caudal rami cylindrical and shorter than the anal somite, with the group of lateral setae located at end of rami. Cottarellicaris sanctiangeli Bruno \& Cottarelli sp. nov. fits with the genus diagnosis except for the female P3 endopod, which is slightly shorter than the first segment of the corresponding exopod instead of being as long as or longer.

Cottarellicaris sanctiangeli sp. nov. differs from its congeners in the morphology of the male P4 endopod, which has the general structure of the genus, but also has a distinctive and characterizing inner tip (apically curved) and, mainly, the proximal outgrowth is thin and as long as the apical lamellar outgrowth (a feature never recorded in any other species of the genus). The affinities of the new species with the eleven known species of Cottarellicaris can be detected for the following morphological features (although some of these features were not described/illustrated in the older descriptions or could have been misinterpreted, such as the presence of a spine or tip on the P5 inner corner, see below):

i) Cuticular windows on the cephalothorax and urosomites of both sexes are missing in the new species and in C. hera, C. etrusca, C. numidiensis, C. andalusica, C. aphroditis, C. stellae, C. oligoalina, C. gallicus and C. rivi; they are present in both sexes in C. luciae and C. sibaritica.

ii) P1 basis of the new species with inner small seta and lamellar hook near the endopod insertion in the male, and only one seta in the female. This dimorphic feature is present in species widely scattered within the distribution area of the genus: $C$. aphroditis from a Greek island, $C$. sibaritica from Southern Italy and C. luciae from Sicily.

iii) The endopod P3 of females is shorter than the first segment of the corresponding exopod only in the new species and in C. numidiensis.

iv) Male P3 structure and ornamentation: the outer margin of exp-1 has two groups of one (proximal) and four (distal) spinules in the new species and in C. aphroditis. The other species with two groups of spinules are C. stellae (two and five), C. luciae (one and two), C. numidiensis (one and two), and only one distal group in the remaining species.

v) Endopod P4 of male with a pointed inner tip carrying at its outer border two outgrowths, the distal one being an elongate lamella with undulating margins: this morphology occurs in all species except C. etrusca, C. sibaritica, C. aphroditis and C. andalusica where the outer outgrowth is missing. The species with two outgrowths differ for the number of curved spiniform processes/spines forming a row on the inner side of the basis, which are three in C. sanctiangeli Bruno \& Cottarelli sp. nov., C. stellae, C. luciae, C. hera, C. numidiensis and C. gallicus, four in C. rivi and C. oligoalina.

vi) the shape of P5 is dimorphic in C. sanctiangeli Bruno \& Cottarelli sp. nov., as it occurs in all Cottarellicaris, but the armature is similar and represented by a spiniform seta on the inner tip and, along the distal margin from inner to outer: two long setae, one short and pointed seta, one long basipodal seta.

The inner spiniform seta/spine is also present in both sexes of $C$. rivi and C. luciae; all the other species of the genus have a curved tip except $C$. numidiensis, where the male has a spiniform seta and the female a curved tip. It could be argued that this element is a spinule rather than a spine, as the groundpattern of Parastenocarididae is represented by four elements, i.e., the basipodal seta and three exopodal setae or spines, one of which is sometimes missing, as it occurs for instance for Proserpinicaris specincola Bruno \& Cottarelli sp. nov. However, it is difficult to detect if this element is a large spinule or a spine without a good SEM analysis, which is not available for C. rivi and C. luciae; nonetheless the only SEM image we obtained for $C$. sanctiangeli sp. nov. suggests the element is indeed a spine.

The affinities between C. sanctiangeli Bruno \& Cottarelli sp. nov. and its geographically closest congener, C. sibaritica (a species collected from the estuarine interstitial of a stream at 13-15 km distance from the two caves hosting $C$. sanctiangeli sp. nov.) are limited to the armature of P1 basis of both sexes, and to the female P4 endopod shape and ornamentation. Cottarellicaris luciae, collected 
in Sicily, is morphologically the closest species, although the shape of the male P3 is different (stouter in $C$. luciae, with different number of outers spinules, i.e., one and a longitudinal row of 2-3) and the female P3 endopod is much longer in C. luciae; the caudal rami carry seven setae in C. luciae and six in $C$. sanctiangeli sp. nov.; finally, $C$. luciae has the typical cuticular windows on cephalothorax and urosomites, which are missing in $C$. sanctiangeli sp. nov.

Stammericaris vincentimariae Bruno \& Cottarelli sp. nov. fits well with the emended description of the genus (Bruno et al. 2017; but see also Schminke 2013). The basis of P1 has an inner seta in both sexes and a hook in males. The outer margin of male P3 exp-1 in males has a proximal and distal group of, respectively, two and four spinules. The male P3 apophysis is about twice as long as the thumb. Stammericaris vincentimariae sp. nov. is morphologically distinguishable from its congeners primarily by the presence of one seta on the $7^{\text {th }}$ antennular segment of the male, a character shared only by S. lorenzae (although in the descriptions of the oldest species, viz. S. stammeri, S. acherusia, S. phreatica, the male A1 is not illustrated, nor described) and by the morphology of the P4 in males: the innermost spinule of the basis inner row is inserted transversally instead of longitudinally; the endopod curved plate tip is bifid instead of pointy and the distal outgrowth is flattened instead of being a seta. Other distinctive characters for the genus are the hyaline membrane surrounding the male $\mathrm{P} 3$ apophysis and the caudal rami with a strong pointed apical apophysis. The endopod $\mathrm{P} 3$ of females is much shorter than half of exp-1, it is much shorter than the endopod of any other species of the genus. The affinities of the new species with the ten known species of Stammericaris can be detected for the following morphological features:

i) Cuticular windows on the cephalothorax and urosomites of both sexes are missing in the new species and in S. pasquinii, S. orcina, S. amyclaea; they are present in S. diversitatis, S. lorenzae and S. trinacriae (for the latter species, windows are wrongly reported as missing in the redescription by Bruno et al. (2017), but visible in the SEM picture of the male cephalosome in Bruno et al. 2017: fig. 12c) and on the cephalosome of the male of $S$. destillans. Cuticular windows also are apparently lacking in S. acherusia, S. stammeri, S. phreatica, but this feature might have been overlooked in the older descriptions.

ii) A strong dorsal pointed apophysis on the caudal rami is present in the new species and in S. diversitatis, S. lorenzae and S. pasquinii.

iii) The basis P1 carries a hook and one seta in males and one seta in females, which is the most common condition in the genus; there is only one small seta in both sexes in S. lorenzae; one hook in the male and one seta in the female of $S$. destillans (however, the basal ornamentation was probably not recorded or drawn for some of the less-recently described species).

iv) Outer margin of P3 male exp-1 proximally and distally with group spinules in the new species and all the other ones, except in $S$. destillans, which has spinules only proximally, and in $S$. trinacriae, which does not have spinules.

v) P3 apophysis long, with a rounded tip and slightly curved inwards, twice as long as the thumb or even longer in the new species and all the other species of the genus except $S$. stammeri, where the apophysis is as long as the thumb.

vi) Male $\mathrm{P} 4$ basis with an inner row of curved spinules decreasing in size laterally: there are three spinules in the new species and in S. diversitatis, S. trinacriae, S. lorenzae, S. pasquinii, S. amyclaea, S. stammeri; four in S. orcina, S. phreatica; two in S. destillans, S. acherusia. Stammericaris vincentimariae sp. nov. also has a spiniform process on the inner margin projecting inwards, which is a unique feature of this species.

vii) The male $\mathrm{P} 4$ endopod in $S$. vincentimariae sp. nov. is a curved plate with a pointed inner tip carrying at its outer border two outgrowths, as it is typical of the genus; in most cases the distal outgrowth is a feathered or plain seta, while in S. vincentimariae sp. nov. it is a denticled lamella; the distal outgrowth 
BRUNO M.C. et al., New Parastenocarididae (Copepoda, Harpacticoida) from Southern Italy

is reduced to a small lobe in $S$. destillans and the proximal outgrowth is missing in S. orcina; the endopodal tip is bifid in the new species and $S$. diversitatis.

The new species is morphologically closer to $S$. pasquinii: they both share the same ornamentation of the P1 basis in both sexes, the lack of integumental windows on urosomites and cephalothorax, a dorsal apophysis on the caudal rami and two rows of two and four spinules along the outer margin of the male P3 exp-1. The molecular analysis supports these morphological affinities by showing a possible sister clade relationship between the two species. Stammericaris destillans, which according to the molecular analysis is in turn close to this clade, is morphologically very different from $S$. vincentimariae Bruno \& Cottarelli sp. nov.: in S. destillans the P4 of males carries only two curved spinules on the basis, the largest one closest to the endopod and the P3 exp-1 has only one group of proximal spinules, the P2 endopod in both sexes is small, curved, with only one apical seta. Stammericaris destillans is also smaller than all the other Stammericaris. The new species also has a close morphological affinity with $S$. diversitatis from epikarstic drip of a cave in Sicily. The two species share a very similar male P3 and P4 endopod, the caudal rami with a strong dorsal pointed apophysis; they differ for the shape and number of setae of P5, which is rectangular, with a short seta on the inner corner for males and a spiniform process for females in S. diversitatis, the P5 is trapezoidal, with an inner spiniform process in both sexes of $S$. vincentimariae sp. nov. These two species also differ in the ornamentation of the P1 basis, as $S$. diversitatis does not have the lamellar hook on the inner margin. In this case, however, the morphological affinities are not supported by the molecular analysis.

We attributed the new species from Grave Grubbo to the genus Proserpinicaris because this species has only one, long pointed process inserted between the endopod and exopod of P4 (see following chapter). Proserpinicaris specincola Bruno \& Cottarelli sp. nov. is easily distinguishable from P. proserpina, which is the species geographically closest (type locality: Pertosa Cave, Salerno Province, southern Italy, $175 \mathrm{~km}$ from the type locality of $P$. specincola sp. nov., collected also from several sites and habitats from surface and groundwater of Campania, Apulia and Central Italy (Ruffo \& Stoch 2005) by the morphology of P4 endopod and P3 in males. The new species has some affinities with other taxa from Southern Italy and Sardinia, viz. P. kalypso (Sicily) and P. admete (Sardinia) in the morphology of enp P4 which is spiniform, pointing inwards and crenulated in the proximal half (in P. vincentimariae sp. nov. and P. calypso) or in the proximal and distal third (in P. admete). The P3 of males of these three species, however, differs. The affinities of the new species with the eleven known species of Proserpinicaris can be detected from the following morphological features:

i) P3 in males: the new species is the only one with the inner margin of exp-1 straight, without beak and/ or one or more chitinous lobes as it occurs in all the other species.

ii) Caudal rami with six setae as in P. kalypso, P. nicolasi, P. phyllura, P. cantabrica, P. cruzi, P. gorganensis, P. corgosimhoi, P. karanovici.

iii) Shape and size of $\mathrm{P} 4$ endopod in males (a pointed segment, crenulated in the proximal half, as long as the first segment of the corresponding exopod), which is most similar to that of a Proserpinicaris sp. from Turkey (Fig. 16g), which, however, is very different for the other diagnostic characters (male P3 in males, female P4 enp, caudal rami of both sexes).

Taking into account only the known species, the P4 endopod of the new species is similar to that of $P$. kalypso and, to a lesser extent, P. mangini and P. phyllura. The new species is overall morphologically more similar to P. kalypso, even if for Proserpinicaris the interspecific differences are not as defined as it occurs for the genera Cottarellicaris and Stammericaris. Even though, at least for the European species, it is difficult to define the interspecific differences, as all these species are quite similar, the new species is characterized by the smaller size (smaller than all the other Italian species), the thin cuticle and the lack of integumental windows on urosomites and cephalothorax. Dorsal windows are present 
in both sexes of the Korean and Indian species (P. young, P. wangpi, P. imjin, P. ondali, P. corgosinhoi, P. karanovici), in P. admete, P. amalasuntae, P. hispanica, Proserpinicaris sp. from Asinara Island and Proserpinicaris sp. from Turkey and in the female of $P$. kalypso. The cephalothoracic window alone is present in both sexes of $P$. proserpina and a window on the last urosomite is present in P. cruzi (male, the female of this species is unknown); windows are missing in $P$. ima. For the remaining (European) species, the descriptions do not mention the cuticular windows and the drawings do not show them either; however, these features might have been overlooked in the older descriptions.

\section{Controversial aspects of the genus Proserpinicaris}

The validity of the genus Proserpinicaris, as redefined by Karanovic et al. (2012) is controversial. For Karanovic et al. (2012), the most important synapomorphic character of the genus is represented by the presence of a hyaline structure (a pointed process in P. specincola sp. nov.) inserted on the male leg 4 basis, between the exopod and endopod (Fig. 13d). Corgosinho et al. (2012) described this character as a synplesiomorphy of the subfamily Fontinalicaridinae Schminke, 2010, making the genus Proserpinicaris polyphyletic, and rejected the validity of this genus. In fact, in the original description of the subfamily Fontinalicaridinae, Schminke (2010) clearly stated that "on the basis of male leg 4 Parastenocaridinae have (if present) spinules either medially of the endopod or at its base; Fontinalicaridinae have them between endopod and exopod". Furthermore, Schminke (2010) adds "in 25 species there is just one spinule between endopod and exopod". Proserpinicaris should, therefore, belong to this latter group of Fontinalicaridinae. However, this group comprises species which, although characterized by having only one spinule inserted between enp and exp, differ in our opinion from those of Proserpinicaris for the remaining diagnostic characters.

We consider the redescription of the genus by Karanovic et al. (2012) as valid, but think it should be narrowed down to those species morphologically close to the type species $P$. proserpina (as redescribed in Bruno \& Cottarelli 1998) for the main diagnostic characters, i.e., species with one long hyaline process on the male P4 basis and a stout male P3, with an exopodal distal apophysis finger-type, shorter than the thumb. As a consequence, some of the species attributed to Proserpinicaris should be considered species inquirenda, such as P. corgosinhoi, and P. hispanica.

It must be taken into account that in Proserpinicaris the basis of male P4 carries two 'appendices' or "elements' ("Anhänge" according to Lang 1948), it is not always easy to tell apart the endopod from the hyaline process (Corgosinho et al. 2012). However, P. proserpina, type species for the genus, and the species of Proserpinicaris discussed in this paper, share a clearly recognisable endopod, inserted outwardly to the hyaline structure, as well as all the diagnostic feature of the genus (see the section "Taxonomic definition and affinities of three new species"), and are clearly representatives of the genus. To reinforce this attribution, we analysed the morphology of the endopod P4 in male copepodites at the last larval stage (i.e., CV) of P. proserpina (collected in Bracciano lake, Latium, Italy, Fig. 16a), P. admete (hyporheic of several streams in Sardinia, Italy, Fig. 16b), P. amalasuntae (Bolsena Lake, Latium, Italy, Figs 16c, 15d), and a new Proserpinicaris sp. from the hyporheic of a stream in Anatolia,Turkey (Figs 16e, 15f). For the latter species, we also show the adult male P4 (Fig. 16g), to confirm the affinities with the other species discussed here. In all the copepodites of Proserpinicaris, the endopod is a pointed, strong appendix with one or two groups of marginal or transversal spinular rows, which will develop in the complex structure of the adult and is always represented by a pointed segment with a crenulated or denticled section. It is not likely that an ornamented immature endopod, as the one present in the above-mentioned CV of Proserpinicaris, could undergo a regressive transformation and become the thinner and simpler hyaline structure. We also examined the male CV P4 endopod of an undescribed new genus (Cottarelli, unpublished) of Parastenocarididae not related to Proserpinicaris, where the P4 endopod is similar to the one of Proserpinicaris, but unornamented, to underline how the general morphology of the P4 endopod is similar at the CV stage even in unrelated genera, and the genuscharacterizing ornamentation develops in the adult phase. The hyaline structure (as all the sexually 
dimorphic characters) apparently appears in the mature stage as well, as documented by the analysis of all the copepodite stages present in P. phyllura by Glatzel (1991): in this species the male copepodite V (Glatzel 1991: fig. 8h) carries only the endopod; the endopod is therefore already recognisable even if the hyaline structure is not yet present. This structure is present in the adult of $P$. phyllura, and inserted in the 'ususal' position, i.e., between the endopod and exopod. These data, in our opinion, help distinguish the endopod from the hyaline structure, the former being the one with the most complex structure (even in the last larval stages, if they can be observed). We also noticed an interesting anomaly, which helps distinguishing the endopod from the hyaline structure: one of the two P4 in the CV of the undescribed Turkish Proserpinicaris (Fig. 16 e-f) carries a hyaline structure, inserted between the endopod and exopod (arrowed in Fig. 16e). This hyaline structure is not the outer seta present on the P1-P4 basipodite of all Parastenocarididae, it is inserted exactly where the hyaline structure will be present in the adults; its presence in the fifth copepodite stage could be due to a developmental anomaly or asynchrony, but it might provide an indication of the position where the hyaline structure will develop in the following adult stage.

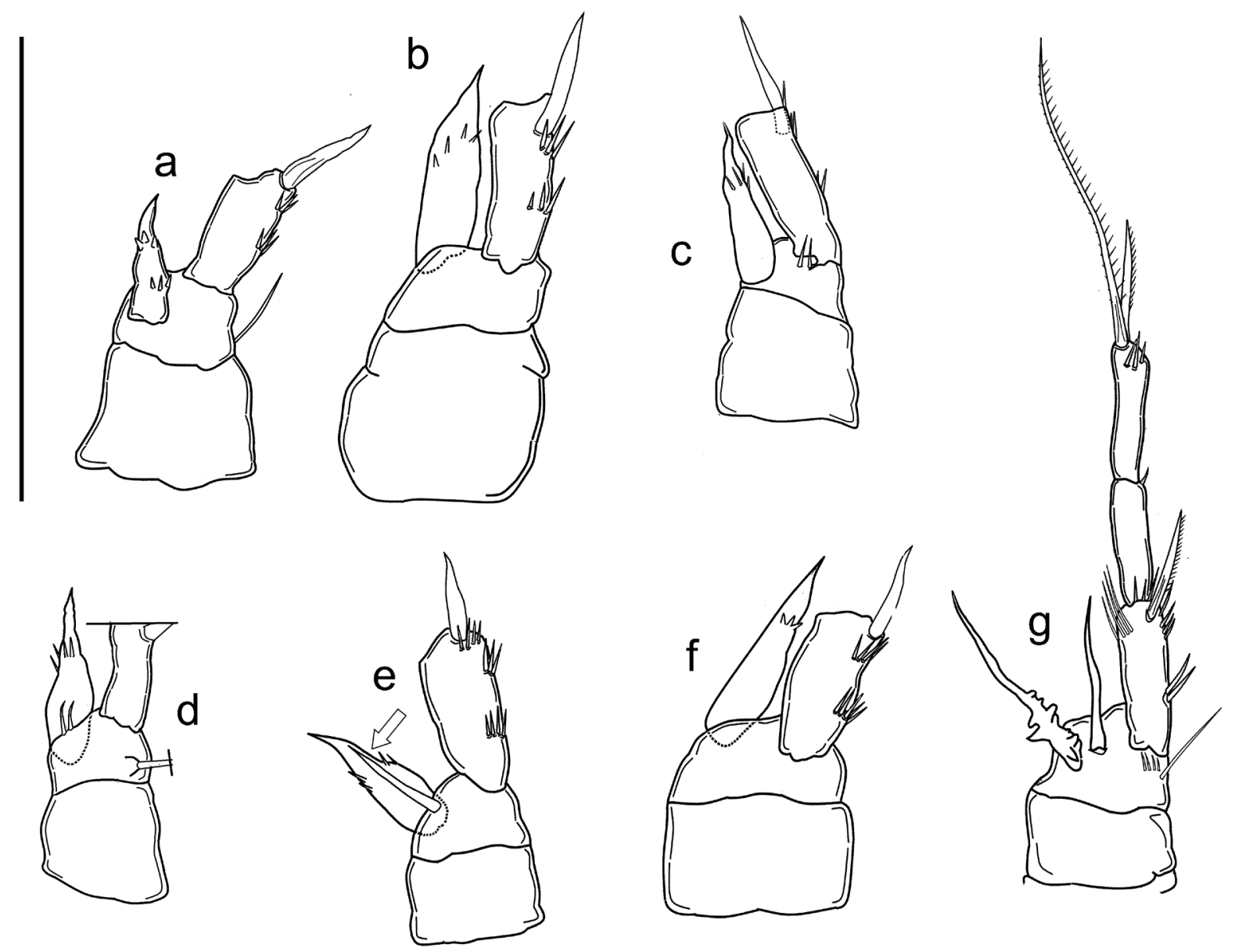

Fig. 16. a-f. $\widehat{O}$, copepodid V stage, $\mathrm{P} 4$ basis, first exopodal segment and enp. a. Proserpinicaris proserpina (Chappuis, 1938) (Bracciano Lake). b. Proserpinicaris admete (Cottarelli, Fasano, Mura \& Saporito, 1980) (Sardinia). c-d. Proserpinicaris amalasuntae (Bruno \& Cottarelli, 1998) (Bolsena Lake). e-f. Proserpinicaris sp. (Turkey), hyaline structure arrowed. g. Proserpinicaris sp. (Turkey), ठิ, P4. Scale bar: $50 \mu \mathrm{m}$. 


\section{Phylogenetic relationships}

The phylogenetic analyses provided results supporting the current, morphology-based taxonomical arrangement of the family Parastenocarididae. Within the ingroup, P. amalasuntae, the only representative of the subfamily Fontinalicaridinae included in our analysis is clearly separated from a well-supported Parastenocaridinae clade. The latter, in turn, is subdivided in two sister subclades, one including the studied populations of Cottarellicaris sanctiangeli Bruno \& Cottarelli sp. nov. and the other including all the analysed Stammericaris spp. Our data confirm what was reported in a recent phylogenetic analysis of all the genera included in the subfamily Parastenocaridinae (Corgosinho et al. 2017), where Cottarellicaris and Stammericaris are reported as a monophyletic separate group within the subfamily. The relationships among the analysed Stammericaris spp. are rather unexpected, since the species are not grouped according to a clear geographical pattern, nor in complete agreement with their morphological affinity. Future analyses, including further species and populations of Cottarellicaris and Stammericaris, will help to better understand the phylogenetic and phylogeographical relationships existing among these taxa.

Interestingly, within the Cottarellicaris sanctiangeli clade, the samples collected in Grotta superiore di Sant'Angelo and Vucco Ucciardo are genetically identical, and slightly diverge from those collected in Grotta del Banco di ferro. This is in good accordance to the hydrological setting of the area, with Grotta superiore di Sant'Angelo and Vucco Ucciardo located within the same watershed and thus actually hosting a single, continuous population of $C$. sanctiangeli Bruno \& Cottarelli sp. nov., whereas Grotta del Banco di ferro is located on an isolated, albeit close, hydrological complex.

Species belonging to different subfamilies (i.e., the Fontinalicaridinae genus Proserpinicaris and the Parastenocaridinae genera Stammericaris and Cottarellicaris) had the highest pairwise $p$-distance values of COI sequences (ranging between 26.4 to $32 \%$ ). Pairwise distances between genera belonging to the same subfamily ranged between $22.4 \%$ (C. sanctiangeli Bruno \& Cottarelli sp. nov. vs S. diversitatis) and $25.9 \%$ (C. sanctiangeli sp. nov. vs $S$. vincentimariae Bruno \& Cottarelli sp. nov.); these molecular distances are comparable to those observed between different Australian parastenocaridin genera by Karanovic \& Cooper (2011a). Conversely, we observed remarkably high interspecific distances between species belonging to the genus Stammericaris, with pairwise distance values ranging between $12.9 \%$ (S. pasquinii vs $S$. vincentimariae sp. nov.) and $26.2 \%$ ( $S$. pasquinii vs $S$. diversitatis). These distances are significantly higher than those observed between species belonging to the parastenocaridid genus Kinnecaris Jakobi, 1972 (Karanovic \& Cooper 2011b), but fall within the range known for congeneric species belonging to other harpacticoid families (e.g., Miraciidae: see Karanovic et al. 2015a, Ameiridae: see Karanovic et al. 2015b and Harpacticidae: see Vecchioni et al. 2019)

\section{Distribution and ecology}

The distributional range of the collected genera and species is preliminary, as the fauna of Parastenocarididae from caves of large areas of Southern Italy is still poorly known. The genus Cottarellicaris has a typically perimediterranean distribution: most of the known species are endemic for Southern Italy $(C$. hera and C. sibaritica), Sicily (C. luciae) and Sardinia (C. oligoalina, C. rivi, C. stellae); the species collected outside Italy are endemic for Spain (C. andalusica), France (C. gallicus), Greece (C. aphroditis) and Algeria (C. numidiensis). Most of the species were collected in the interstitial habitat of rivermouths (eight out of twelve). C. sanctiangeli Bruno \& Cottarelli sp. nov. is the third stygobitic species of the genus, together with C. gallicus, from a cave in the Pyrenèes, and C. numidiensis from drip pools in a cave in West Algeria (Chappuis \& Rouch 1959; Rouch 1987).

The genus Stammericaris has so far been collected mainly in Italy, where nine out of eleven species are endemic; S. stammeri and S. phreatica were found in Spain/France and Romania/Czech Republic, respectively (Chappuis 1936, 1937; Rouch 1986). The genus is common in caves, with three species 
BRUNO M.C. et al., New Parastenocarididae (Copepoda, Harpacticoida) from Southern Italy

(S. diversitatis, $S$. destillans, $S$. vincentimariae Bruno \& Cottarelli sp. nov.) collected exclusively in caves (epikarst, rimstone pools) (Cottarelli et al. 2012; Bruno et al. 2017), whereas the remaining two (S. orcina, $S$. trinacriae) were collected in rimstone pools and lacustrine psammal, and rimstone pools and phreatic waters, respectively (Chappuis 1938; Cottarelli \& Drigo 1972; Bruno et al. 2017).

The genus Proserpinicaris has a wide distribution; it was initially defined as Palaearctic with the center of diversity in southern Europe (Karanovic et al. 2012), being present in Scandinavia, France, Italy, Portugal, Balkanic area, Spain, and also in Japan. The collection of four species from Korea (Lee \& Chang 2009; Karanovic et al. 2012) and two species from India (Totakura et al. 2014), widened the distribution of this genus in Asia. Several undescribed species (Cottarelli, unpublished data) were collected in Taiwan and the Fiji Islands. The genus is present in caves in the Palaearctic region with three out of the 23 known species ( $P$. cantabrica, $P$. mangini, $P$. proserpina) and in Asia with two species (P. ondali in Korea, P. corgosinhoi in India) (Rouch 1986, 1992; Karanovic et al. 2012; Totakura et al. 2014); all the remaining species were collected from a phreatic (wells) or hyporheic habitat. Prosepinicaris proserpina, initially collected in a cave, was later on recorded as widely distributed in the interstitial habitat of streams and lakes as well as in phreatic waters (Ruffo \& Stoch 2005). Proserpinicaris specincola Bruno \& Cottarelli sp. nov. is the first Proserpinicaris recorded from an evaporitic cave; to our knowledge, the only other Parastenocarididae collected from this type of caves is Stammericaris trinacriae, collected from epikarstic drip in Sicily (Bruno et al. 2017).

The distance between the caves where the three new species were collected and the coast ranges from 16 to $22 \mathrm{~km}$. The new species could have colonized (following Coineau \& Boutin 1992) the karstic system during marine introgression phases from ancient rivermouths during the Miocene.

Similarly to what we recently recorded for caves in Sicily (Bruno et al. 2017, 2018), each one of the investigated cave hosts only one endemic species of Parastenocarididae. While Stammericaris vincentimariae Bruno \& Cottarelli sp. nov. and Proserpinicaris specincola Bruno \& Cottarelli sp. nov. were each collected in only one cave, Cottarellicaris sanctiangeli Bruno \& Cottarelli sp. nov. apparently has a wider distribution, having been collected in three caves within a range of $7 \mathrm{~km}$, with two of them (Grotta superiore di Sant'Angelo and Vucco Ucciardo) at about $1.3 \mathrm{~km}$ distance from each other. These two caves are located in the same hydrogeological complex and in the same watershed (Coscile Stream) and are probably hydrologically connected, thus explaining the shared presence of this species. The third cave (Grotta del Banco di ferro), however, is more distant from the preceding two (about $7 \mathrm{~km}$ ) and located in a different hydrogeological complex and in a different watershed (Raganello Stream). All Italian Cottarellicaris, with the exception of the new species, have been collected only near to rivermouth, even in slightly brackish water (Cottarelli \& Bruno 1994; Berera \& Cottarelli 2003; Cottarelli et al. 2008): the presence of $C$. sanctiangeli sp. nov. in the Grotta del Banco di ferro could be due to the colonization of the two cave complexes by the same ancestral population, occurring in slightly brackish water covering, or adjacent to, both cave systems, which are presently at only $16-17 \mathrm{~km}$ from the sea. Interestingly, Grotta dello Scoglio, the cave where S. vincentimariae Bruno \& Cottarelli sp. nov. was collected, is only about 0.35 and $1.1 \mathrm{~km}$ distant (distance measured from the caves opening) from two of the caves hosting C. sanctiangeli sp. nov. (Grotta superiore di Sant'Angelo and Vucco Ucciardo, respectively). The three caves belong to the same upper Triassic-Lias limestone and dolostone unit. Endemisms over short spatial scales have been reported for epikarstic copepods: for instance, a significant fraction of the copepod species found in four Slovenian and one West Virginian caves occurred over a maximum linear extent of $100 \mathrm{~m}$ (Pipan \& Culver 2007). Bruno et al. (2018) analysed the scales of distribution of epikarstic copepods, recording how most of the taxa collected in Sicily are endemic to one cave, with very different distributions over short spatial scales (tens of kilometers) and, within each cave, the distribution varied even over distances of a few meters, underlining the 'blocky' distribution of epikarstic copepod fauna (Bruno et al. 2018 and references therein). 
If we take into account the geomorphological and hydrological setting of the investigated caves, it appears that $C$. sanctiangeli Bruno \& Cottarelli sp. nov. lives in the epikarst (having been collected in fossil caves, Grotta del Banco di ferro and Grotta Vucco Ucciardo), but also in a non-strictly epikarstic habitat (Grotta superiore di Sant'Angelo is an active cave, percolating water probably is mixed with groundwater forming the water table). Stammericaris vincentimariae Bruno \& Cottarelli sp. nov. and P. specinicola Bruno \& Cottarelli sp. nov. were collected in active caves, but we could not assess whether the specimens collected in the pools derived from the epikarstic drip or the water table; we can only remark that $P$. specincola sp. nov. is the first representative of the genus recorded in an evaporitic cave, and that the genus Stammericaris typically has epikarstic species (Bruno et al. 2017, 2018; Cottarelli et al. 2012). The caudal rami of $S$. vincentimariae sp. nov. carry an apical apophysis, similarly to what recorded for S. diversitatis; it was hypothesized that such a structure could help anchor the animal to the substratum, preventing vertical drift (Cottarelli et al. 2012). For S. vincentimariae sp. nov., we cannot exclude that this morphology has the same function.

A discrepancy exists between the molecular phylogeny, and the distribution and habitat of the investigated species. Whereas the phylogenetic affinity of S. diversitatis and S. trinacriae was not unexpected, since both species are endemic to western Sicily and were collected from similar habitats, the phylogenetic relationships between the epikarstic/karstic S. vincentimariae Bruno \& Cottarelli sp. nov. and the psammic S. pasquinii from volcanic lakes in Central Italy is more difficult to interpret. However, there are probably other species distributed in caves and other groundwater habitats that could fill the apparent biogeographic and phylogenetic gaps between these two taxa, and change the intrageneric phylogenetic affinities. We thus hereby encourage other copepodologists to expand the currently available knowledge on Palaearctic parastenocaridid copepods and to increase the parastenocaridid DNA sequences database to help solve these and similar phylogenetic conundrums.

\section{Acknowledgements}

The authors would like to thank Dr Fabio Stoch for the loan of specimens of Cottarellicaris sp. from Montecristo Island, Tuscany. RG and MTS would like to thank Antonio Larocca and the "Gruppo Speleologico Sparviere" (Alessandria del Carretto, CS); Mario Vincenzo Benedetto, Fabio Selvaggi and the "Gruppo Speleo-Archeologico Aquila Libera" (Cassano allo Ionio, CS); Francesco Ferraro and the "Gruppo Speleologico Le Grave" (Verzino, KR); Angelo Iemmolo and Speleo Club Ibleo (Ragusa, RG) for helping in all the sampling campaigns, and the Ente Parco Nazionale del Pollino for authorizing the speleological activities in Grotta del Banco di ferro. Finally, the authors wish to thank the two anonymous referees, whose comments greatly helped to improve the manuscript and figures.

\section{References}

Akaike H. 1974. A new look at the statistical model identification. IEEE Transactions on Automatic Control 19: 716-723. https://doi.org/10.1109/TAC.1974.1100705

Berera R. \& Cottarelli V. 2003. Two new species of interstitial harpacticoids from southern Italy and proposal of a new Parastenocaris species-group. Italian Journal of Zoology 70: 261-268. https://doi.org/10.1080/11250000309356527

Bruno M.C. \& Cottarelli V. 1998. Description of Parastenocaris amalasuntae n. sp. and new data on Parastenocaris proserpina and Parastenocaris pasquinii from subterranean waters of central Italy (Copepoda, Harpacticoida). Italian Journal of Zoology 65: 121-136. https://doi.org/10.1080/11250009809386732

Bruno M.C., Cottarelli V., Hauffe H.C., Rossi C., Obertegger U., Grasso R. \& Spena M.T. 2017. Morphological and phylogenetic analyses of epikarstic Parastenocarididae (Copepoda: Harpacticoida) 
BRUNO M.C. et al., New Parastenocarididae (Copepoda, Harpacticoida) from Southern Italy

from two Sicilian caves, and description of a new Stammericaris. Zootaxa 4350: 251-283. https://doi.org/10.11646/zootaxa.4350.2.3

Bruno M.C, Cottarelli V., Grasso R., Latella L., Zaupa S. \& Spena M.T. 2018. Epikarstic crustaceans from some Italian caves: endemisms and spatial scales. Biogeographia - The Journal of Integrative Biogeography 33: 1-18. https://doi.org/10.21426/B633035812

Chappuis P.A. 1936. Subterrane Harpacticoiden aus Jugoslawien. Buletinul Societatii de Stiinte din Cluj 8: 386-398.

Chappuis P.A. 1937. Subterrane Harpacticoiden aus Nord-Spanien. Buletinul Societatii de Stiinte din Cluj 8: 556-571.

Chappuis P.A. 1938. Subterrane Harpacticoiden aus Süd-Italien. Buletinul Societatii de Stiinte din Cluj 9: 153-181.

Chappuis P.A. \& Rouch R. 1959. Harpacticoïdes cavernicoles des Basses-Pyrénées. Annales de Spéléologie 14: 197-211.

Coineau N. \& Boutin C. 1992. Biological processes in space and time. Colonization, evolution and speciation in interstitial stygobionts. In: Camacho A.I. (ed.) The Natural History of Biospeleology: 423451. Monografias 7, CSIC Ed., Museo Nacional de Ciencias Naturales, Madrid.

Corgosinho P.H.C., Martínez Arbizu P. \& Previattelli D. 2012. Establishment of a new genus for Parastenocaris itica (Copepoda, Harpacticoida) from El Salvador, Central America, with discussion of the Parastenocaris fontinalis and P. proserpina groups. Iheringia Série Zoologia 102 (4): 401-411. https://doi.org/10.1590/S0073-47212012005000009

Corgosinho P.H.C., Schizas N.V., Previattelli D., da Rocha C.E.F. \& dos Santos-Silva E.N. 2017. A new genus of Parastenocarididae (Copepoda, Harpacticoida) from the Tocantins River basin (Goiás, Brazil), and a phylogenetic analysis of the Parastenocaridinae. Zoosystematics and Evolution 93: 167-187. https://doi.org/10.3897/zse.93.11602

Cottarelli V. \& Drigo E. 1972. Sulla presenza di Parastenocaris orcina Chappuis (Cop. Harpacticoida) in acque interstiziali del Lago di Bracciano. Notiziario del Circolo Speleologico Romano 17: 51-54.

Cottarelli V. \& Bruno M.C. 1994. Parastenocaris rivi n. sp. di acque iporreiche dell'Isola di S. Pietro (Sardegna). [Crustacea, Copepoda, Harpacticoida]. Richerche zoologiche della nave oceanografica 'Minerva' (C.N.R.) sulle isola circumsarde. XXI. Annali del Museo civico di Storia naturale Giacomo Doria 90: 509-519.

Cottarelli V., Bruno M.C. \& Berera R. 2008. Two new species of Parastenocaris (Copepoda, Harpacticoida, Parastenocarididae) from groundwater of Sardinia and Sicily. Crustaceana 81: 537-555. https://doi.org/10.1163/156854008784092274

Cottarelli V., Bruno M.C. \& Berera R. 2010. First record of a Parastenocarididae from Thailand and description of a new genus (Copepoda: Harpacticoida). Journal of Crustacean Biology 30: 478-494. https://doi.org/10.1651/09-3201.1

Cottarelli V., Bruno M.C., Spena M.T. \& Grasso R. 2012. Studies on subterranean copepods from Italy, with descriptions of two new epikarstic species from a cave in Sicily. Zoological Studies 51: 556-82.

Cunningham C.W. 1997. Can three incongruence tests predict when data should be combined? Molecular Biology and Evolution 14: 733-740. https://doi.org/10.1093/oxfordjournals.molbev.a025813

Farris J.S., Källersjö M., Kluge A.G. \& Bult C. 1995. Testing significance of incongruence. Cladistics 10: 315-319. https://doi.org/10.1111/j.1096-0031.1994.tb00181.x 
Felsenstein J. 1985. Confidence limits on phylogenies: An approach using the bootstrap. Evolution 39 (4): 783-791. https://doi.org/10.1111/j.1558-5646.1985.tb00420.x

Ferrari F.D. \& Ivanenko V.N. 2008. The identity of protopodal segments and the ramus of maxilla 2 of copepods (Copepoda). Crustaceana 81: 823-835.

Folmer O., Black M., Hoeh W., Lutz R. \& Vrijenhoek R. 1994. DNA primers for amplification of mithocondrial cytochrome c oxidase subunit I from diverse metazoan invertebrates. Molecular Marine Biology and Biotechnology 3: 294-299.

Forti P. \& Sauro U. 1996. The gypsum karst of Italy. International Journal of Speleology 25 (3/4): 239-250. https://doi.org/10.5038/1827-806X.25.3.18

Galdenzi S. \& Maruoka T. 2019. Sulfuric acid caves in Calabria (South Italy): Cave morphology and sulfate deposits. Geomorphology 328: 211-221. https://doi.org/10.1016/j.geomorph.2018.12.014

Gasparo F. 1980. Il fenomeno carsico nel territorio comunale di Cassano allo Jonio (Provincia di Cosenza). Atti e Memorie della Commissione Grotte "Eugenio Boegan” 19: 79-116.

Glatzel T. 1991. Neue morphologische Aspekte und die Copepodid Stadien von Parastenocaris phyllura Kiefer (Copepoda, Harpacticoida). Zoologica Scripta 20: 375-393.

https://doi.org/10.1111/j.1463-6409.1991.tb00302.x

Guindon S. \& Gascuel O. 2003. A simple, fast, and accurate algorithm to estimate large phylogenies by maximum likelihood. Systematic Biology 52: 696-704. https://doi.org/10.1080/10635150390235520

Huys R. \& Boxshall G.A. 1991. Copepod Evolution. The Ray Society, London.

International Commission on Zoological Nomenclature. 1999. International Code of Zoological Nomenclature, Fourth Edition: Adopted by the International Union of Biological Sciences. The International Trust for Zoological Nomenclature, London.

Jakobi H. 1972. Trends (Enp. P4) innerhalb der Parastenocarididen (Copepoda Harpacticoidea). Crustaceana 22: 127-146.

Karanovic T. \& Cooper S.J.B. 2011a. Third genus of parastenocaridid copepods from Australia supported by molecular evidence (Copepoda, Harpacticoida). In: Defaye D., Suarez-Morales E. \& Vaupel Klein J.C. (eds) Studies on Freshwater Copepoda: a Volume in Honour of Bernard Dussart: 293-337. Brill, Leiden. https://doi.org/10.1163/9789004188280_014

Karanovic T. \& Cooper S.J.B. 2011b. Molecular and morphological evidence for short range endemism in the Kinnecaris solitaria complex (Copepoda: Parastenocarididae), with descriptions of seven new species. Zootaxa 3026: 1-64. https://doi.org/10.11646/zootaxa.3026.1.1

Karanovic T., Cho J.-L. \& Lee W. 2012. Redefinition of the parastenocaridid genus Proserpinicaris (Copepoda: Harpacticoida), with description of three new species from Korea. Journal of Natural History 46: 1573-1613. https://doi.org/10.1080/00222933.2012.681316

Karanovic T., Kim K. \& Grygier M.J. 2015a. A new species of Schizopera (Copepoda: Harpacticoida) from Japan, its phylogeny based on the mtCOI gene and comments on the genus Schizoperopsis. Journal of Natural History 49: 2493-2526. https://doi.org/10.1080/00222933.2015.1028112

Karanovic T., Eberhard S., Cooper S.J.B. \& Guzik M.T. 2015b. Morphological and molecular study of the genus Nitokra (Crustacea, Copepoda, Harpacticoida) in a small palaeochannel in Western Australia. Organisms Diversity \& Evolution 5: 65-99. https://doi.org/10.1007/s13127-014-0193-3

Klimchouk A.B., Palmer A.N., De Waele J., Auler A. \& Audra P. 2017. Hypogene Karst Regions and Caves of the World. Springer, Cham. https://doi.org/10.1007/978-3-319-53348-3 
BRUNO M.C. et al., New Parastenocarididae (Copepoda, Harpacticoida) from Southern Italy

Kumar S., Stecher G., Li M., Knyaz C. \& Tamura K. 2018. MEGA X: Molecular Evolutionary Genetics Analysis across computing platforms. Molecular Biology and Evolution 35: 1547-1549.

https://doi.org/10.1093/molbev/msy096

Lanfear R., Calcott B., Ho S.Y.W. \& Guindon S. 2012. PartitionFinder: combined selection of partitioning schemes and substitution models for phylogenetic analyses. Molecular Biology and Evolution 29: 16951701. https://doi.org/10.1093/molbev/mss020

Lang K. 1948. Monographie der Harpacticiden. Håkan Ohlsson, Lund.

Larkin M.A., Blackshields G., Brown N.P., Chenna R., McGettigan P.A., McWilliam H., Valentin F., Wallace I.M., Wilm A., Lopez R., Thompson J.D., Gibson T.J. \& Higgins D.G. 2007. Clustal W and Clustal X version 2.0. Bioinformatics 23: 2947-2948. https://doi.org/10.1093/bioinformatics/btm404

Lee J. \& Chang C.Y. 2009. Two groundwater copepods of the genus Parastenocaris (Harpacticoida, Parastenocarididae) from South Korea. Animal Cells and Systems 13 (2): 169-178.

https://doi.org/10.1080/19768354.2009.9647209

Pipan T. \& Culver D.C. 2007. Copepod distribution as an indicator of epikarst system connectivity. Hydrogeology Journal 15: 817-822. https://doi.org/10.1007/s10040-006-0114-4

Ranga Reddy Y., Totakura V.R. \& Corgosinho P.H.C. 2014. Himalayacaris alaknanda n. gen., n. sp. (Copepoda: Harpacticoida: Parastenocarididae) from the Hyporeic Zone of a Himalayan River, Northern India. Journal of Crustacean Biology 34: 801-819. https://doi.org/10.1163/1937240X-00002281

Richterich P. 1998. Estimation of errors in "raw" DNA sequences: a validation study. Genome Research 8: 251-259. https://doi.org/10.1101/gr.8.3.251

Ronquist F., Teslenko M., Van der Mark P., Ayres D.L., Darling A., Höhna S., Larget B.R., Liu L.F., Suchard M.A. \& Huelsenbeck J.P. 2012. MrBayes v. 3.2: efficient bayesian phylogenetic inference and model choice across a large model space. Systematic Biology 61: 539-542.

https://doi.org/10.1093/sysbio/sys029

Rouch R. 1986. Copepoda: harpacticoids souterrains des eaux douce continentals. In: Botosaneanu L. (ed.) Stygofauna Mundi. A Faunistic, Distributional, and Ecological Synthesis of the World Fauna Inhabiting Subterranean Waters (Including the Marine Interstitial): 321-3555. E.J. Brill, Leiden.

Rouch R. 1987. Copépodes harpacticoïdes stygobies d'Algérie. Bijdragen tot de Dierkunde 57: 71-86. https://doi.org/10.1163/26660644-05701007

Rouch R. 1992. Parastenocaris mangini n. sp., nouvel harpacticoide (Copépodes) stygobie des Pyrénées. Crustaceana 63 (3): 306-312. https://doi.org/10.1163/156854092X00460

Ruffo S. \& Stoch F. 2005. Checklist e distribuzione della fauna italiana. Memorie del Museo Civico di Storia Naturale di Verona, $2^{\text {nd }}$ series, Section Life Sciences 16, Museo Civico di Storia Naturale, Verona.

Schminke H.K. 2010. High-level phylogenetic relationships within Parastenocarididae (Copepoda, Harpacticoida). Crustaceana 83: 343-367. https://doi.org/10.1163/001121610X12627655658168

Schminke H.K. 2013. Stammericaris Jakobi, 1972 redefined and a new genus of Parastenocarididae (Copepoda, Harpacticoida). Crustaceana 86: 704-717. https://doi.org/10.1163/15685403-00003196

Swofford D.L. 2003. PAUP*. Phylogenetic Analysis Using Parsimony (and Other Methods). Version 4. Sinauer Associates, Sunderland, Massachusetts.

Tang C.Q., Leasi F., Obertegger U., Kieneke A., Barraclough T.G. \& Fontaneto D. 2012. The widely used small subunit $18 \mathrm{~S}$ rDNA molecule greatly underestimates true diversity in biodiversity surveys of the meiofauna. Proceedings of the National Academy of Sciences of the United States of America 109: 16208-16212. https://doi.org/10.1073/pnas.1209160109 
Totakura V.R., Ranga Reddy Y. \& Shaik S. 2014. Three new species of Parastenocarididae (Crustacea, Copepoda, Harpacticoida) from India. Zootaxa 3821: 501-537.

https://doi.org/10.11646/zootaxa.3821.5.1

Vecchioni L., Marrone F., Rodilla M., Belda E.J. \& Arculeo M. 2019. An account on the taxonomy and molecular diversity of a marine rock-pool dweller, Tigriopus fulvus (Copepoda, Harpacticoida). Ciencias Marinas 45 (2): 59-75. https://doi.org/10.7773/cm.v45i2.2946

Walter T.C. \& Boxshall G. 2019. World of Copepods Database. Parastenocarididae Chappuis, 1940. Available from WoRMS http://www.marinespecies.org/aphia.php [accessed 15 Mar. 2019].

Manuscript received: 27 January 2020

Manuscript accepted: 11 May 2020

Published on: 23 July 2020

Topic editor: Rudy Jocqué

Desk editor: Kristiaan Hoedemakers

Printed versions of all papers are also deposited in the libraries of the institutes that are members of the EJT consortium: Muséum national d'histoire naturelle, Paris, France; Meise Botanic Garden, Belgium; Royal Museum for Central Africa, Tervuren, Belgium; Royal Belgian Institute of Natural Sciences, Brussels, Belgium; Natural History Museum of Denmark, Copenhagen, Denmark; Naturalis Biodiversity Center, Leiden, the Netherlands; Museo Nacional de Ciencias Naturales-CSIC, Madrid, Spain; Real Jardín Botánico de Madrid CSIC, Spain; Zoological Research Museum Alexander Koenig, Bonn, Germany; National Museum, Prague, Czech Republic. 